\title{
Global Growth and National Urban Development with Housing
}

\section{Wei-Bin ZHANG}

\section{ARTICLE INFO}

\section{Article History:}

Date Submitted: 05.03.2020

Date Accepted: 27.03.2020

JEL Classification:

F20,

O41.

Keywords:

Trade Pattern,

Residential Structure,

Growth,

Capital Accumulation

\begin{abstract}
The purpose of this study is to examine dynamic interactions between economic growth, housing markets, residential distribution and international trade. The paper builds a multi-country growth model with economic geography and capital accumulation. It makes an original contribution to the literature of spatial economic growth by integrating economic geography and housing markets into a multi-country growth model with microeconomic foundations. The four basic models - the Solow growth model, the Oniki-Uzawa trade model, the Alonso urban model, and the Muth housing model - in economic theory are integrated within a comprehensive framework. This unique feature implies that many basic issues of spatial economics can be examined in a single framework. We show that the dynamics of the J-country world economy is described by $\mathbf{J}$ differential equations. We also simulate the global economy with three countries. Comparative dynamic analysis shows how different exogenous changes in the national preferences, technologies, land, and labor affect the global growth, national development, and spatial geography.
\end{abstract}

\footnotetext{
${ }^{1}$ Prof., Ritsumeikan Asia Pacific University, Japan, wbz1@apu.ac.jp
} 


\section{Introduction}

National economies are now globally connected through international trade in goods and services. A national economy cannot be effectively explained as an isolated island even in an approximate sense. The current impact of the Convid-19 is an example of how an exogenous shock may change global economies simultaneously. This implies that it is necessary to have an economic theory which treats the world as an integrated whole. Nevertheless, there are only a few rigorous economic models of global growth built on microeconomic mechanisms. As observed by Findlay (1984), the pure theory of international trade in the classical literature of economic theory failed to take any consideration of the connection between economic growth and international trade. There are some trade models with capital movements (MacDougall, 1960; and Kemp, 1961). But almost all the early models are limited to static and one-commodity frameworks. A rigorous dynamic model which takes account of accumulating capital stocks was initially developed by Oniki and Uzawa (Oniki and Uzawa, 1965; Johnson, 1971; Frenkel and Razin, 1987; Jensen, 1994; Valdés, 1999; and Nishimura and Shimomura, 2002). The growth models with endogenous physical capital are primarily concerned with the process of world capital accumulation and distribution. They are applied to study the dynamics of capital accumulation and various balances of payments accounts (see also, Ethier and Svensson, 1986; Bhagwati, 1991; and Wong, 1995). An exception is the approach by Zhang (1995, 2008) which integrates national economic structure into account. This paper generates Zhang's model on the basis of neoclassical grow theory.

In recent years some other trade models have been proposed to make systematic treatments of capital accumulation in the context of international economics. Nevertheless, most of trade models with endogenous capital are still either limited to two-country or small open economies (e.g., Wong, 1995; Jensen and Wong, 1998; Obstfeld and Rogoff, 1998; and Naito and Ohdoi, 2011). As far as capital accumulation and trade pattern determination are concerned, our study follows the Oniki-Uzawa framework (see also, Ikeda and Ono, 1992; Sorger, 2002; and Vellutini, 2003). We analyze trade issues within the framework of a simple international macroeconomic growth model with perfect capital mobility. Lucas (1988) recognizes the necessity of analyzing economic geography and economic growth as a connected whole, even though not much progress in this direction has been made in the literature of economic theories. If one follows 
the well-accepted analytical framework, i.e., the Ramsey growth model, this task is, if not impossible, not easy. This study applies an alternative approach to household behavior. The approach enables us to solve spatial problems with space and capital accumulation under free trade.

As economic geography has not been properly integrated into economic growth theory, effects of trade are not theoretically modelled in the literature of international growth theory. This study integrates Alonso's model, the key model in urban economics, with the neoclassical international growth theory. Since Alonso (1964) published his important work in 1964, many urban models with residential structures have been developed. The early literature includes, for instance, Muth (1969), Mills (1967), Beckmann (1969), Solow (1973), and others. Most of urban land-use models with microeconomic foundations study economic geography with housing and residential distribution but neglect production aspects of urban dynamics. On the other hand, there are many studies of urban growth and dynamics (e.g., Richardson, 1973; Rabenau, 1979; and Henderson, 1985). Zhang (2008b) integrates neoclassical growth with Alonso's model. This study is to synthesize the main ideas in neoclassical urban economics and neoclassical growth trade theory in a comprehensive framework on the basis of Zhang's previous works just referred. As pointed out by Henderson et al. (2001), a proper understanding of spatial economics is essential for explaining economic growth. This study explains interactions of global growth, trade, housing markets with residential distribution over space. Indeed, over the past three decades, economic growth with housing and economic geography has caused a lot of attention in urban economics and regional science (Henderson and Thisse, 2004; and Capello and Nijkamp, 2004). Yet, there are not yet proper analytical framework for spatial evolution and growth with capital accumulation on the basis of microeconomic mechanism. As pointed out by Baldwin and Martin (2004: 2675-6), "Many of the most popular economic geography models focus on labor. ... These are unsuited to the study of growth. The key to all sustained growth is the accumulation of human capital, physical capital and/or knowledge capital - with the accumulation of knowledge capital, i.e., technological progress having a privileged position. We thus need a model in which capital exists and its stock is endogenous." Arnott (1980: 53) points outs: "In the last decade the static theory of residential urban location and land use has been extensively developed. The theory has generated many useful insights, but because it ignores growth and durability of housing and urban infrastructure there are many urban 
phenomena it cannot explain." The situation is not much improved in the current literature of urban economics. What Fujita and Thisse (2002: 389) observed about one decade ago is still valid today: "Clearly, space and time are intrinsically mixed in the process of economic development. However, the study of their interaction is a formidable task. Because either agglomeration or growth is a complex phenomenon by itself, one should expect any integrated analysis to face many conceptual and analytical hurdles. Not surprisingly, therefore, the field is still in its infancy, and relevant contributions have been few." This study makes a unique contribution to the literature of spatial growth theory.

Location-dependent housing is essential for understanding modern economies. Housing is the largest component of nonhuman wealth for households and housing services are a fundamental component of the household consumption. For instance, in the United States, real estate investment account for over $50 \%$ of total private investment and real estate assets represent just under $60 \%$ of the nation's wealth. Almost 70\% of U.S. real estate is residential (see, DiPasquale and Wheaton, 1996). Housing has a set of intrinsic properties, which make it significantly from any other goods. Operation of housing market is varied in different regions and countries. There is a large literature on durable housing in spatial context (e.g., Muth, 1973; Anas, 1978, 1982; Hockman and Pines, 1980; Brueckner, 1981; Arnott, 1987; Brueckner and Pereira, 1994; Arnott et al., 1999; Braid, 2001). Nevertheless, as argued by Brito and Pereira (2002), the link between the housing market and long-term growth has been neglected in the literature. This study also tries to make a contribution to the issue. We deal with many issues within a comprehensive framework, making a unique contribution to the literature of trade and economic geography by synthesizing the main ideas in the four key models in the literature of theoretical economics within a comprehensive framework. The four models are the Solow growth model, the Oniki-Uzawa trade model, the Alonso urban model and the Muth housing model. The rest of the paper is organized as follows. Section 2 defines the basic model. Section 3 shows how we solve the dynamics with economic geography, examines how some variables change over space, and studies the dynamic properties of the model when the production function is specified in the Cobb-Douglas form. Section 4 carries out comparative dynamic analysis to examine the impact of changes in some parameters on the motion of the global economy. Section 5 concludes the study. The appendix proves the main results in Section 3. 


\section{The Model}

The model is a combination of the basic features of the four key models, the Solow growth model, the Oniki-Uzawa model, the Alonso urban model, and the Muth housing model in the neoclassical growth theory and urban economics. Although it is based on Zhang's urban model and trade model $(1995,2008 \mathrm{~b})$, the model in this study combines the trade model and urban model within a comprehensive framework. It is well known that most neoclassical models are extensions and generalizations of the pioneering works of Solow (1956). In the standard neoclassical growth model, capital and labor are substitutes for one another with the result that the long-run growth path of the economy is one of full employment. The Solow model has been extended and generalized in many studies (e.g., Burmeister and Dobell, 1970, and Zhang, 2008a). The production side of our model is based on the neoclassical growth approach. Nevertheless, we use an alternative approach to consumer behavior as explained later on. As far as urban structures are concerned, we follow the standard residential land-use model. We select industrial good to serve as numeraire. As we assume that the transportation cost of workers to the city is dependent on the travel distance, land rent for housing should be spatially different. Moreover, it is assumed that the countries produce a homogenous tradable commodity (see also Ikeda and Ono, 1992). There is only one (durable) good in the global economy under consideration. Households own assets of the economy and distribute their incomes to consume and save. Production sectors or firms use capital and labor. Exchanges take place in perfectly competitive markets. Production sectors sell their product to households or to other sectors and households sell their labor and assets to production sectors. Factor markets work well; factors are inelastically supplied and the available factors are fully utilized at every moment. Saving is undertaken only by households, which implies that all earnings of firms are distributed in the form of payments to factors of production. We omit the possibility of hoarding of output in the form of non-productive inventories held by households. All savings volunteered by households are absorbed by firms. We require savings and investment to be equal at any point of time. The system consists of multiple countries, indexed by $j=1, \ldots, J$. Each country has a fixed labor force, $N_{j},(j=1, \ldots, J)$. Let $K_{j}(t)$ and $\bar{K}_{j}(t)$ stand for respectively the capital stocks employed and the wealth owned by country $j$. We also introduce $K_{j i}(t)$ and $K_{j h}(t)$ to represent the capital stocks employed by the industrial sector and housing sector. We denote wage and interest rates by $w_{j}(t)$ and $r_{j}(t)$, respectively, in the $j$ th country. In the free trade 
system where transaction costs are neglected, the interest rate is identical throughout the world economy, i.e., $r(t)=r_{j}(t)$.

\section{Behavior of producers}

First, we describe behavior of the production sections. We assume that there are two input factors, physical capital and labor at each point of time $t$. The production functions, $F_{j}(t)$, are specified as follows:

$F_{j}(t)=A_{j} K_{j i}^{\alpha_{j}}(t) N_{j}^{\beta_{j}}, A_{j}>0, \alpha_{j}+\beta_{j}=1, \alpha_{j}, \beta_{j}>0, j=1, \cdots, J$,

in which $A_{j}$ is country $j$ 's total productivity. Markets are competitive; labor and capital earn their marginal products, and firms earn zero profits. The rate of interest, $r(t)$, and wage rates, $w_{j}(t)$, are determined by markets. Hence, for any individual firm $r(t)$ and $w_{j}(t)$ are given at each point of time. The production sector chooses the two variables $K_{j i}(t)$ and $N_{j}$ to maximize its profit. The marginal conditions are given by:

$r(t)+\delta_{k j}=A_{j} \alpha_{j} k_{j}^{-\beta_{j}}(t), w_{j}(t)=A_{j} \beta_{j} k_{j}^{\alpha_{j}}(t),(1)$

where $\delta_{k j}$ are the depreciation rate of physical capital in country $j$ and $k_{j}(t) \equiv K_{j i}(t) / N_{j}$.

\section{Housing production and residential distribution}

An individual may reside at only one location. The only spatial characteristic of any location in a country that directly matters is the distance from the city center. Due to the complexity of considering both space and time in a general equilibrium framework, at this initial stage we simplify the structure of economic geography by following the Alonso model. The population within each country is homogenous and there is no international migration. There are studies with multiple income classes (e.g., Beckman, 1969; Solow, 1973; Beckmann and Papageorgiou, 1989; Anas, 1990; and Tabuchi and Thisse, 2002). For an equilibrium to exist, the households within a country must achieve the same utility level regardless of where they locate. All the markets are perfectly competitive. The system is geographically linear and consists of two parts - 
the central business district (CBD) and the residential area. The isolated state consists of a finite strip of land extending from the CBD with constant unit width. We assume that all economic activities are concentrated in the CBD. The households occupy the residential area. We assume that the CBD is located at the left-side end of the linear territory. As we will get the same conclusions if we locate the $\mathrm{CBD}$ at the center of the linear system, the specified urban configuration will not affect our discussion. We now describe housing production and behavior of households. First, we introduce

$L_{j}$ — the fixed (territory) length of country $j$;

$\omega_{j}$ - the distance from the CBD to a point in country $j$ 's residential area, $0 \leq \omega_{j} \leq L_{j}$;

$R_{j}\left(\omega_{j}, t\right)$ and $R_{j h}\left(\omega_{j}, t\right)$ - the land rent and housing rent per household at location $\omega_{j} ;$

$\bar{k}_{j}\left(\omega_{j}, t\right)$ and $s_{j}\left(\omega_{j}, t\right)$ - the wealth owned by and the saving made by the household at location $\omega_{j}$, respectively;

$c_{j}\left(\omega_{j}, t\right)$ - the consumption of the household at location $\omega_{j}$;

$n_{j}\left(\omega_{j}, t\right)$ and $L_{j h}\left(\omega_{j}, t\right)$ - the residential density and the lot size of the household at location $\omega_{j}$.

We assume that all housing is residential housing. Residential housing assets play a dual role in the economy. First, residential housing assets are used as a durable consumption good. They are the source of housing services. Second, residential housing assets are used as a mechanism for the intertemporal transfer of wealth, which generates both rents and capital gains through housing appreciation. We limit ourselves to a simple case of housing technology. To explain spacedependent gradients for residential density and capital-land ratios, we follow Muth's approach. We consider a commodity "housing" rather than land in describing dwelling conditions. Housing is produced with land and non-land inputs. Households have a derived demand for land, dependent on both preferences for housing and technical characteristics of housing production function. Let 
us denote $c_{j h}\left(\omega_{j}, t\right)$ housing service received by the household at location $\omega_{j}$. We specify the housing service production function as follows:

$c_{j h}\left(\omega_{j}, t\right)=A_{j h} k_{j h}^{\alpha_{j h}}\left(\omega_{j}, t\right) L_{j h}^{\beta_{j h}}\left(\omega_{j}, t\right), \alpha_{j h}+\beta_{j h}=1, \alpha_{j h}, \beta_{j h} \geq 0,(2)$

where $k_{j h}\left(\omega_{j}, t\right)$ is the input level of capital per household at location $\omega_{j}$. All the characteristics of houses such as the size of a lot and the size of a house can be changed instantaneously without costs. Hence the capital-land ratio is always perfectly adjusted. Our approach is mainly based on Anas (1978). Further issues related to the durability of real estates and its costly conversion and replacements are further discussed by Anas (see also Arnott, 1980; Arnott et al., 1999; and Glaeser and Gyourko, 2005). See also Lin et al. (2004). The marginal conditions are given by:

$r+\delta_{k}=\frac{\alpha_{j h} R_{j h} c_{j h}}{k_{j h}}, R_{j}=\frac{\beta_{j h} R_{j h} c_{j h}}{L_{j h}}, 0 \leq \omega_{j} \leq L_{j}$

According to the definitions of $L_{j h}$ and $n_{j}$, we have:

$n_{j}\left(\omega_{j}, t\right)=\frac{1}{L_{j h}\left(\omega_{j}, t\right)}, 0 \leq \omega_{j} \leq L_{j} .(4)$

The total capital stock employed by the housing sector is equal to the sum of the capital stocks for housing over space at any point of time. The relationship between $k_{h j}\left(\omega_{j}, t\right)$ and $K_{h j}(t)$ is thus given by:

$K_{j h}(t)=\int_{0}^{L_{j}} n_{j}\left(\omega_{j}, t\right) k_{j h}\left(\omega_{j}, t\right) d \omega_{j} \cdot(5)$

\section{Household behavior}

Each worker may get income from land ownership, wealth ownership and wages. In order to define incomes, it is necessary to determine land ownership structure. It can be seen that land properties may be distributed in multiple ways under various institutions. To simplify the model, we assume the land is equally owned by the population. This implies that the revenue from land is 
equally shared among the population (see also Kanemoto, 1980). The total land revenue $\bar{R}_{j}(t)$ is given by:

$$
\bar{R}_{j}(t)=\int_{0}^{L_{j}} R_{j}\left(\omega_{j}, t\right) d \omega_{j}
$$

The income from land per household $\bar{r}_{j}(t)$ is given by $\bar{r}_{j}(t)=\bar{R}_{j}(t) / N_{j}$. Consumers make decisions on choice of lot size, consumption level of commodity as well as on how much to save. This study uses the approach to consumers' behavior proposed by Zhang in the early 1990s (Zhang, 1993). This approach makes it possible to solve many national, international, urban, and interregional economic problems, such as growth problems with heterogeneous households, multisectors, and preference changes, which are analytically intractable by the traditional approaches in economics. Let $\bar{k}_{j}\left(\omega_{j}, t\right)$ stand for per capita wealth (excluding land) owned by the typical household in at location $\omega_{j}$. Each household at $\omega_{j}$ obtains income:

$y_{j}\left(\omega_{j}, t\right)=r(t) \bar{k}_{j}\left(\omega_{j}, t\right)+w_{j}(t)+\bar{r}_{j}(t), 0 \leq \omega_{j} \leq L_{j},(6)$

from the interest payment, $r k_{j}$, and the wage payment, $w_{j}$, and the land rent income, $\bar{r}_{j}$. We call $y_{j}\left(\omega_{j}, t\right)$ the current income in the sense that it comes from consumers' wages and current earnings from ownership of wealth. The sum of income that consumers are using for consuming, saving, or travels are not necessarily equal to the current income because consumers can sell wealth to pay, for instance, the current consumption if the current income is not sufficient for buying food and touring the country. The total value of the wealth that a consumer at location $\omega_{j}$ can sell to purchase goods and to save is equal to $p_{i}(t) k_{j}\left(\omega_{j}, t\right)$, with $p_{i}(t)=1$ at any $t$. Here, we assume that selling and buying wealth can be conducted instantaneously without any transaction cost. The disposable income is then equal to

$\hat{y}_{j}\left(\omega_{j}, t\right)=y_{j}\left(\omega_{j}, t\right)+\bar{k}_{j}\left(\omega_{j}, t\right) \cdot(7)$

The disposable income is used for saving and consumption. It should be noted that the value, $\bar{k}_{j}\left(\omega_{j}, t\right)$, (i.e., $\left.p_{i}(t) \bar{k}_{j}\left(\omega_{j}, t\right)\right)$, in the above equation is a flow variable. Under the assumption that selling wealth can be conducted instantaneously without any transaction cost, we 
may consider $\bar{k}_{j}$ as the amount of the income that the consumer at $\omega_{j}$ obtains at time $t$ by selling all of his wealth. Hence, at time $t$ the consumer has the total amount of income equaling $\hat{y}_{j}$ to distribute between consuming and saving. It should also be remarked that in the growth literature, for instance, in the Solow model, the saving is out of the current income, $y_{j}$, while in this study the saving is out of the disposable income which is dependent both on the current income and wealth. The implications of this approach are similar to the Keynesian consumption function and models based on the permanent income hypothesis, which are empirically much more valid than the approaches in the Solow model or the in Ramsey model.

At each point of time, a consumer at location $\omega_{j}$ distributes the total available budget among the leisure time, $T_{j h}\left(\omega_{j}\right)$, housing, $c_{j h}\left(\omega_{j}, t\right)$, saving, $s_{j}\left(\omega_{j}, t\right)$, consumption of industrial goods, $c_{j}\left(\omega_{j}, t\right)$. Here, we assume that the leisure is only dependent on the residential location as the work time is fixed and equal for each household, in disregard of residential location. After the work time is decided, the households decide the time distribution between leisure and travel to work. As we assume that the travel time from the CBD to the residential location is only related to the distance and neglect any other effects such on technological change, infrastructure improvement, and congestion on the travel time form the CBD to the residential area, the leisure time, which is equal to the fixed total time minus the travel time, is only related to location. Let $T_{0}$ and $\Gamma_{j}\left(\omega_{j}\right)$ respectively stand for the total available time for travel and leisure and the time spent on traveling between the residence and CBD. We have:

$T_{j h}\left(\omega_{j}\right)=T_{0}-\Gamma_{j}\left(\omega_{j}\right)$

The budget constraint is given by:

$R_{j h}\left(\omega_{j}, t\right) c_{j h}\left(\omega_{j}, t\right)+c_{j}\left(\omega_{j}, t\right)+s_{j}\left(\omega_{j}, t\right)=\hat{y}_{j}\left(\omega_{j}, t\right)$

Equation (8) means that the consumption and saving exhaust the consumers' disposable personal income.

Location choice is closely related to the existence and quality of such physical environmental attributes as open space and noise pollution as well as social environmental quality. 
We assume that utility level, $U_{j}\left(\omega_{j}, t\right)$, of the household at location $\omega_{j}$ is dependent on $T_{j h}\left(\omega_{j}\right)$, $c_{j h}\left(\omega_{j}, t\right), s_{j}\left(\omega_{j}, t\right)$, and $c_{j}\left(\omega_{j}, t\right)$ as follows:

$U_{j}\left(\omega_{j}, t\right)=\theta_{j}\left(\omega_{j}, t\right) T_{j h}^{\sigma_{j}}\left(\omega_{j}, t\right) c_{j}^{\xi_{0 j}}\left(\omega_{j}, t\right) c_{j h}^{\eta_{0 j}}\left(\omega_{j}, t\right) s_{j}^{\lambda_{0 j}}\left(\omega_{j}, t\right),(9)$

in which the positive parameters, $\sigma_{j}, \xi_{0 j}, \eta_{0 j}$, and $\lambda_{0 j}$ are a typical person's elasticity of utility with regard to leisure time, industrial goods, housing, and saving at $\omega_{j}$. We call $\sigma_{j}, \xi_{0 j}, \eta_{0 j}$, and $\lambda_{0 j}$ propensities to use leisure time, to consume goods, to consume housing, and to hold wealth, respectively.

The desirability of residential location is affected by consumption amenities, such as public services, accessibilities, local transportation systems, pollution, and human relations. This study incorporates amenity into the consumer location decision by assuming that amenity is a function of residential density. This study does not take account of externalities for producers. For instance, firms often prefer to locate to other firms. An explicit introduction of externalities will make the spatial structure far more complicated. In the literature of urban economics, various externalities have been analyzed (see, Henderson, 1974; Upton, 1981; and Abdel-Rahman, 2004). Hence, the distance from the CBD is related to the inconvenience of the distance and the value of the amenity of the surrounding area. Glaeser et al. (2001: 27) point out: "Most urban scholars think of cities as offering positive agglomeration benefits in the productive sphere, and as having negative agglomeration effects (or congestion effects") on non-work consumption". Their empirical study demonstrates that high amenity cities grown faster than low amenity cities and that the role of urban density in maintaining urban growth is important. This study considers that residential densities may have positive or negative agglomeration effects. We specify the amenity, $\theta_{j}\left(\omega_{j}, t\right)$, at $\omega_{j}$ as follows:

$\theta_{j}\left(\omega_{j}, t\right)=\theta_{1 j} n_{j}^{\mu_{j}}\left(\omega_{j}, t\right), \theta_{1 j}>0$

The function $\theta_{j}\left(\omega_{j}, t\right)$ implies that the amenity level at location $\omega_{j}$ is related to the residential density at the location. 
For simplicity, we restrict the analysis to the case that all households obtain the same level of utility at any point of time. The condition of utility equalization is often used in the literature of urban economics. We assume that people can change their residential location freely without any transaction costs and time delay. The conditions that households get the same level of utility at any location at each point of time is represented by:

$U_{j}\left(\omega_{1 j}, t\right)=U_{j}\left(\omega_{2 j}, t\right), 0 \leq \omega_{1 j}, \omega_{2 j} \leq L_{j}$

Maximizing $U_{j}\left(\omega_{j}, t\right)$ subject to the budget constraint (8) yields:

$c_{j}\left(\omega_{j}, t\right)=\xi_{j} \hat{y}_{j}\left(\omega_{j}, t\right), c_{j h}\left(\omega_{j}, t\right)=\frac{\eta_{j} \hat{y}_{j}\left(\omega_{j}, t\right)}{R_{j h}\left(\omega_{j}, t\right)}, s_{j}\left(\omega_{j}, t\right)=\lambda_{j} \hat{y}_{j}\left(\omega_{j}, t\right)$

in which

$\xi_{j} \equiv \rho_{j} \xi_{0 j}, \eta_{j} \equiv \rho_{j} \eta_{0 j}, \lambda_{j} \equiv \rho_{j} \lambda_{0 j}, \rho_{j}=\frac{1}{\xi_{0 j}+\eta_{0 j}+\lambda_{0 j}}$

The above equations mean that the housing consumption, consumption of the good and saving are positively proportional to the available income.

According to the definition of $s_{j}\left(\omega_{j}, t\right)$, the capital accumulation for the household at location $\omega_{j}$ is given by:

$\dot{\bar{k}}_{j}\left(\omega_{j}, t\right)=s_{j}\left(\omega_{j}, t\right)-\bar{k}_{j}\left(\omega_{j}, t\right), 0 \leq \omega_{j} \leq L_{j}$

The equation simply states that the change in the wealth is equal to the savings minus the dissaving.

\section{Balance conditions}

As there is no international migration, each country's total population is distributed over the whole urban area. The population constraints are given by: 
$\int_{0}^{L_{j}} n_{j}\left(\omega_{j}, t\right) d \omega_{j}=N_{j}$

The total consumption of country $j, C_{j}(t)$ is given by:

$\int_{0}^{L_{j}} n_{j}\left(\omega_{j}, t\right) c_{j}\left(\omega_{j}, t\right) d \omega_{j}=C_{j}(t)$.

The national wealth (excluding land) is equal to the total wealth owned by all the households:

$$
\int_{0}^{L_{j}} \bar{k}_{j}\left(\omega_{j}, t\right) n_{j}\left(\omega_{j}, t\right) d \omega_{j}=\bar{K}_{j}(t) .(14)
$$

Let $K(t)$ stand for the capital stocks of the world economy. The total capital stock employed by the world is equal to the wealth owned by the world:

$K(t)=\sum_{j=1}^{J} K_{j}(t)=\sum_{j=1}^{J} \bar{K}_{j}(t)$

where $K_{j}(t) \equiv K_{j i}(t)+K_{j h}(t)$. The trade balances of the economies are given by:

$E_{j}(t)=\left(\bar{K}_{j}(t)-K_{j}(t)\right) r(t) \cdot(16)$

When $E_{j}(t)$ is positive (negative), we say that country $j$ is in trade surplus (deficit). When $E_{j}(t)$ is zero, country $j$ 's trade is in balance. We have thus built the dynamic growth model with endogenous spatial distribution of wealth, consumption and population, capital accumulation and residential location. We now examine dynamic properties of the system.

\section{The Dynamics and Equilibrium}

Before examining the dynamic properties of the system, we show that the dynamics of $J$ economies can be expressed by $J$ differential equations with the following $J$ variables, $k_{1}$ and $\left\{\bar{K}_{j}\right\} \equiv\left(\bar{K}_{2}, \ldots, \bar{K}_{J}\right)$. This result is important as we can follow the dynamics of global economic 
geography and growth with some initial conditions. In the rest of the paper, we omit $\omega$ or/and $t$ in the expressions, wherever without causing confusion.

\section{Lemma}

Assume that the initial distribution of per household's wealth in each country is homogenous over space. The dynamics of the global economy with $J$ countries is determined by:

$$
\begin{aligned}
& \dot{k}_{1}=\Lambda_{1}\left(k_{1},\left\{\bar{K}_{j}\right\}\right), \\
& \dot{\bar{K}}_{j}=\Lambda_{j}\left(k_{1},\left\{\bar{K}_{j}\right\}\right), j=2, \ldots, J,(17
\end{aligned}
$$

in which $\Lambda_{j}$ are functions of $k_{1}$ and $\left\{\bar{K}_{j}\right\}$ explicitly defined in Appendix. At any point of time, all the other variables are determined as unique functions of $k_{1}$ and $\left\{\bar{K}_{j}\right\}$ by the following procedure: $\bar{K}_{1}$ by $(\mathrm{A} 10) \rightarrow \bar{k}_{j}=\bar{K}_{j} / N_{j} \rightarrow k_{j}$ by $(\mathrm{A} 8) \rightarrow K_{j i}=k_{j} N_{j} \rightarrow r$ and $w_{j}$ by $(\mathrm{A} 8) \rightarrow \hat{Y}_{j}$ by $(\mathrm{A} 5) \rightarrow \hat{y}_{j}=\hat{Y}_{j} / N_{j} \rightarrow \hat{R}_{j}$ by (A3) $\rightarrow \bar{r}_{j}=\hat{R}_{j} / N_{j} \rightarrow c_{j s}$ and $s_{j}$ by (10) $\rightarrow k_{j \otimes}$ by (A16) $\rightarrow$ $n_{j}\left(\omega_{j}\right)$ by (A18) and (A19) $\rightarrow R_{j h}\left(\omega_{j}\right)$ by $(\mathrm{A} 17) \rightarrow L_{j h}\left(\omega_{j}\right)=1 / n_{j}\left(\omega_{j}\right) \rightarrow c_{j h}\left(\omega_{j}\right) \rightarrow R_{j}\left(\omega_{j}\right)$ by (3).

The condition that households' wealth within each country is homogeneous over space at $t=0$ is important for us to get explicit expressions of the dynamics.

Although we know how to find solutions of the system, the expressions are too tedious. For illustration, we will simulate the model. Before simulating the model, we discuss some general implications of Lemma 1. The lemma implies that once we solve the $J$ differential equations, we can determine all the other variables, such as the global wealth, global output, trade pattern, national output levels, national housing product, capital distribution between the two sectors within each country, the rate of interest, the wage rates, and each household's income from the land ownership, the income and wealth distribution over space, residential distribution, the total transportation time spent in the system, the leisure time distribution and the total leisure time in 
the economy, land rent distribution, and housing rent distribution. It should be noted that the total travel time, $\widetilde{T}_{j}$, and the total leisure time, $\widetilde{T}_{j h}$, of country $j$ are given by:

$\tilde{T}_{j}=\int_{0}^{L_{j}} n_{j}\left(\omega_{j}\right) \Gamma_{j}\left(\omega_{j}\right) d \omega_{j}, \tilde{T}_{j h}=\int_{0}^{L_{j}} n_{j}\left(\omega_{j}\right)\left(T_{0}-\Gamma_{j}\left(\omega_{j}\right)\right) d \omega_{j}$

As proved in Appendix, if the initial distribution of the wealth in all the countries is homogenous over space, then the per-capita wealth $\bar{k}_{j}\left(\omega_{j}\right)$, and disposable income $\hat{y}_{j}\left(\omega_{j}\right)$, are homogenous over space. That is:

$\bar{k}_{j}\left(\omega_{j 1}, t\right)=\bar{k}_{j}\left(\omega_{j 2}, t\right), \hat{y}_{j}\left(\omega_{j 1}, t\right)=\hat{y}_{j}\left(\omega_{j 2}, t\right), 0 \leq \omega_{j 1}, \omega_{j 2} \leq L_{j}$.

This implies that all residents receive the same income and own the same amount of wealth at each point of time. This property comes from the assumption that we omit transportation costs and the specified landownership structure. If transportation costs are not omitted or/and some other type of landownership are assumed, the property may not hold. Hence, the omission of transportation costs greatly simplifies our dynamic analysis. This is the reason we omit transportation costs and take account of travel time in introducing distance effects in our model. In fact, the omission of transportation costs may not affect the main results of this model, except that the gradients of the residential density curve and land rent may be steeper when transportation costs are taken in account.

From (A18) and (A19) we obtain the residential distribution as follows:

$\frac{n_{j}\left(\omega_{j 1}\right)}{n_{j}\left(\omega_{j 2}\right)}=\left(\frac{T_{j h}\left(\omega_{j 1}\right)}{T_{j h}\left(\omega_{j 2}\right)}\right)^{\beta_{0 j}}, n_{j}(0)=\frac{N_{j} T_{j h}^{\beta_{0 j}}(0)}{\int_{0}^{L_{j}} T_{j h}^{\beta_{j 0}}\left(\omega_{j}\right) d \omega_{j}}, 0 \leq \omega_{j 1}, \omega_{j 2} \leq L_{j}$,

where $\beta_{0 j}=\sigma_{j} /\left(\eta_{j} \beta_{j \eta}-\mu_{j}\right)$. We see that the residential density is invariant over time. This property holds under the assumptions that the population fixed, the land is equally shared among the residents, there are no congestion, no transportation costs, no investment in the transportation infrastructure, and no technological change in transportation systems. If any of these assumptions does not hold, then $n_{j}\left(\omega_{j}\right)$ may become time dependent. For instance, if we introduce 
some technological change on the transportation system, then the residential distribution is not invariant in time.

We now examine the residential density over space. As $T_{j h}\left(\omega_{j 1}\right) / T_{j h}\left(\omega_{j 2}\right)>1$ if $\omega_{j 1}<$ $\omega_{j 2}$, if $\beta_{0 j}>0$, then $n_{j}\left(\omega_{j 1}\right)>n_{j}\left(\omega_{j 2}\right)$. We see that the residential density is lower away from the $\mathrm{CBD}$. As traveling costs more as the residence is further away from the $\mathrm{CBD}$, it is reasonable to observe the declination of the residential density as the distance from the CBD increases. Yet, if $\beta_{j 0}<0$, the residential density distribution is inverse to the case of $\beta_{j 0}>0$ in the sense that the further the residential location is away from the CBD, the higher the density is. To see why this happens, from the definition of $\beta_{j 0}$ we see that the parameter becomes negative only when $\mu_{j}>$ $\eta_{j} \beta_{j \eta}>0$. A positive $\mu_{j}$ means that as the residential density rises, the local attractiveness as residential area is increased. From $\mu_{j}>\eta_{j} \beta_{j \eta}$, the individual welfare is positively strongly affected by, for instance, social interactions among local people and the propensity to use land is low. As people so highly evaluate interacting with each other among locals, the urban residential density becomes higher further away from the CBD. In this study, we limit our examination to the case of $\mu_{j}<\eta_{j} \beta_{j \eta}$ for all countries. In this model, we assume $T_{h}(L)>0$. If the amenity is related only to the social interactions, social interactions impact shapes of the residential distribution. It is Beckmann (1976) who first proposed an urban residential model with social interactions. In his approach, the utility of an individual depends on the average distance to all individuals with whom this person interacts as well as on the amount of land the individual buys on the market. The residential center is not pre-fixed. According to Beckmann's approach, it is possible that the highest density will neither appear at the CBD or at the opposite side of the CBD; instead the highest density may appear somewhere between. Another way to take account of social interactions is proposed by Papageorgiou and Smith (1983). They consider a trade-off between social contacts and land use. The need for social contacts is negatively related to distance and the need for land is negatively affected by crowding. When the propensity to interact with others (which corresponds to $\mu$ in our approach) is large enough, the urban equilibrium configuration becomes unstable.

We also have: 
$\frac{R_{j h}\left(\omega_{j 1}\right)}{R_{j h}\left(\omega_{j 2}\right)}=\left(\frac{n_{j}\left(\omega_{j 1}\right)}{n_{j}\left(\omega_{j 2}\right)}\right)^{\beta_{h}}$

The above equation tells that the ratio of housing rents between any two locations is invariant time, even though $R_{j h}\left(\omega_{j}, t\right)$ is changeable with time. As $n_{j}\left(\omega_{j 1}\right)>n_{j}\left(\omega_{j 2}\right)$, the housing rent declines as the residential area is further away from the CBD. By (10), we have:

$c_{j}\left(\omega_{j 1}\right)=c_{j}\left(\omega_{j 2}\right), \frac{c_{j h}\left(\omega_{j 1}\right)}{c_{j h}\left(\omega_{j 2}\right)}=\frac{R_{j h}\left(\omega_{j 2}\right)}{R_{j h}\left(\omega_{j 1}\right)}, s_{j}\left(\omega_{j 1}\right)=s_{j}\left(\omega_{j 2}\right)$.

The property that consumption of industrial goods is invariant in location but changeable in time comes from that the households of the same country have the same income, the same propensity to consume goods, and the price of the goods are invariant in space. Consumption of housing increases as the residential area is further from the CBD. Within each country the total expenditure on housing by per household $R_{j h}\left(\omega_{j}, t\right) c_{j h}\left(\omega_{j}, t\right)$ is invariant in space but changeable in time:

$R_{j h}\left(\omega_{j 1}, t\right) c_{j h}\left(\omega_{j 1}, t\right)=R_{j h}\left(\omega_{j 2}, t\right) c_{j h}\left(\omega_{j 2}, t\right)$

As the housing rent declines in location, we see that the housing consumption per household increases as the dwelling site is further away from the CBD.

Not only the population density but also the capital intensity per square miles tend to increase as we get closer to the city center. Buildings tend to be higher nearer the CBD. From the results in Appendix it is straightforward to show that the capital-land ratio in any country, $k_{j h}\left(\omega_{j}, t\right) / L_{j h}\left(\omega_{j}, t\right)$, is given by:

$\frac{k_{j h}\left(\omega_{j}, t\right)}{L_{j h}\left(\omega_{j}, t\right)}=k_{j h}\left(\omega_{j}, t\right) n_{j}\left(\omega_{j}, t\right)=\frac{\alpha_{0 j} \hat{y}_{j}(t) T_{j h}^{\beta_{0 j}}\left(\omega_{j}\right)}{r(t)+\delta_{k}}$

where 
$\alpha_{0 j} \equiv \frac{\alpha_{j h} \eta_{j} N_{j}}{\int_{0}^{L_{j}} T_{j h}^{\beta_{0 j}}\left(\omega_{j}\right) d \omega_{j}}>0$

We conclude that the capital-land ratio decreases in the distance from the CBD (see Fujita, 1999: Section 3.7).

\section{Equilibrium and Dynamics of the Global Economy}

As it is difficult to explicitly interpret the analytical results, for illustration we simulate the model. We specify the travel time as a linear function of $\omega_{j}$ by $v_{j} \omega_{j}$, where $1 / v_{j}$ is the speed of the travel. The leisure time is thus given by:

$T_{j h}\left(\omega_{j}\right)=1-v_{j} \omega_{j}, 0 \leq \omega_{j} \leq L_{j}$

where we specify $T_{0}=1$. By (A14) and (A15), we solve:

$n_{j}\left(\omega_{j}\right)=n_{j}(0) T_{j h}^{\beta_{0 j}}\left(\omega_{j}\right), n_{j}(0)=\frac{\left(1+\beta_{0 j}\right) v_{j} N_{j}}{1-\left(1-v_{j} L_{j}\right)^{1+\beta_{0 j}}}$,

where we use $T_{j h}(0)=1$. For simulation, we specify values of the parameters as follows:

$N_{1}=1, N_{2}=3, N_{3}=8, A_{1}=1.4, A_{2}=0.8, A_{3}=0.7, A_{1 h}=1.4, A_{2 h}=0.8, A_{3 h}=0.7$,

$L_{j}=5, \alpha_{1}=0.3, \alpha_{2}=0.32, \alpha_{3}=0.31, \alpha_{1 h}=0.3, \alpha_{2 h}=0.32, \alpha_{3 h}=0.31, \alpha_{1 h}=0.5$,

$\eta_{01}=0.2, \xi_{01}=0.2, \lambda_{01}=0.75, \eta_{02}=0.2, \xi_{02}=0.25, \lambda_{02}=0.7, \eta_{03}=0.2, \xi_{03}=0.3$,

$\lambda_{03}=0.65, \sigma_{j}=0.3, \mu_{j}=-0.1, T_{0}=1, v_{j}=0.05, \delta_{k j}=0.05 .(18)$

Country 1 ,2and 3 's populations are respectively 1,3 and 8 . Country 3 has the largest population. Country 1's total productivities of the two sectors, $A_{1}$ and $A_{1 h}$, are highest, country 2 's second and Country 3's lowest. The countries have the same size of land. We call countries 1,2and 3 respectively as developed, industrializing, and underdeveloped economies (DE, IE, UE). We specify the values of the parameters, $\alpha_{j}$, in the Cobb-Douglas productions approximately 
equal to 0.3. The value is often used in empirical studies (e.g., Miles and Scott (2005), Abel et $a l ., 2007)$. The depreciation rate of physical capital is specified at 0.05 . The DE's propensity to save is 0.75 , The DE's is 0.7 , and the UE's is 0.65 . The amenity parameter, $\mu$, is negative. This implies that the households prefer to living in an area with low residential distribution. The total available time is fixed at unit and $v=0.05$ means that if the total travel time from the CBD to another end of the system will use up 25 per cent of the total available time. Following the Lemma under (18), we calculate the equilibrium values of the location-independent variables as follows:

$$
\begin{aligned}
& r=0.171, C=8.79, F=9.97, K=23.58, k_{1}=2.50, k_{2}=1.24, k_{3}=0.97, F_{1}=1.83, \\
& F_{2}=2.57, F_{3}=5.56, K_{1 i}=2.50, K_{2 i}=3.73, K_{3 i}=7.79, f_{1}=1.84, f_{2}=0.86, \\
& f_{3}=0.69, K_{1 h}=2.66, K_{2 h}=2.61, K_{3 h}=4.29, K_{1}=5.16, K_{2}=6.33, K_{3}=12.08, \\
& \bar{K}_{1}=7.35, \bar{K}_{2}=6.30, \bar{K}_{3}=9.93, C_{1}=1.96, C_{2}=2.25, C_{3}=4.58, w_{1}=1.29, \\
& w_{2}=0.58, w_{3}=0.48, \bar{k}_{1}=7.35, \bar{k}_{2}=2.10, \bar{k}_{3}=1.24, c_{1}=1.96, c_{2}=0.75, c_{3}=0.57, \\
& \bar{r}_{1}=1.37, \bar{r}_{2}=41, \bar{r}_{3}=0.26,
\end{aligned}
$$

where $f_{j} \equiv F_{j} / N_{j}$. The share of the capital employed by the housing sector in each country is lower than the capital stocks employed by the industrial sector. The wage rate and levels of per capita consumption and wealth in the DE are much higher than the corresponding variables in the IE, and The wage rate and levels of per capita consumption and wealth in the UE are lowest. It should be noted that we classify the three economies by their technology and propensities to save, not by the wage rate, income and wealth. The differences in per capita consumption, wealth and wage are consequences of the exogenous technological differences and differences in preferences. We now plot the equilibrium values of the location-dependent variables as in Figure 1. In each country the residential density declines and the housing consumption increases in the distance from the $\mathrm{CBD}$ to the residential site. Both the housing rent and land rent fall in the distance. The housing rent curve is steeper than the land rent. 


\section{Figure 1 The Equilibrium Values of the Location-Dependent Variables}
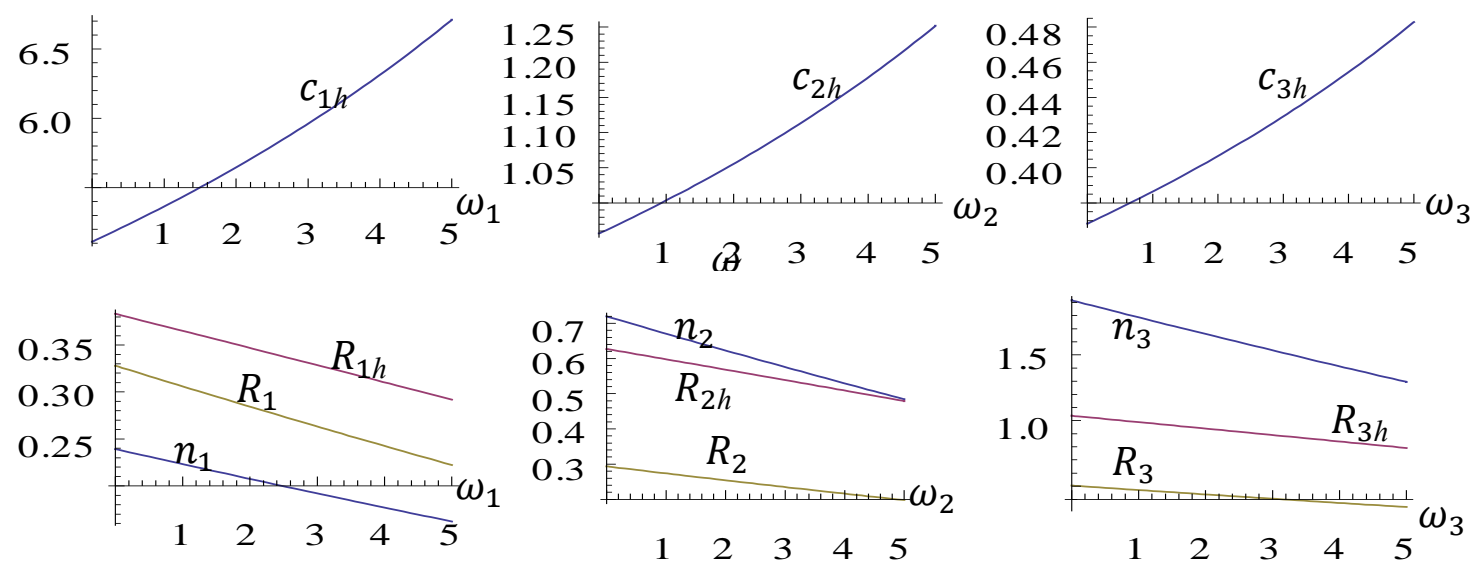

As reality is seldom in stationary state, it is important to see the motion of the system over time and space. As we have already provided the procedure to follow the motion of each variable in the system, it is straightforward to plot the motion with computer. We specify the initial conditions as follows:

$k_{1}(0)=2.2, \bar{K}_{2}(0)=5.2, \bar{K}_{3}(0)=9$.

The initial state is far away from the equilibrium. The motion of the system is given in Figure 2. The system approaches its long-term equilibrium over time.

Figure 2 The Motion of the System
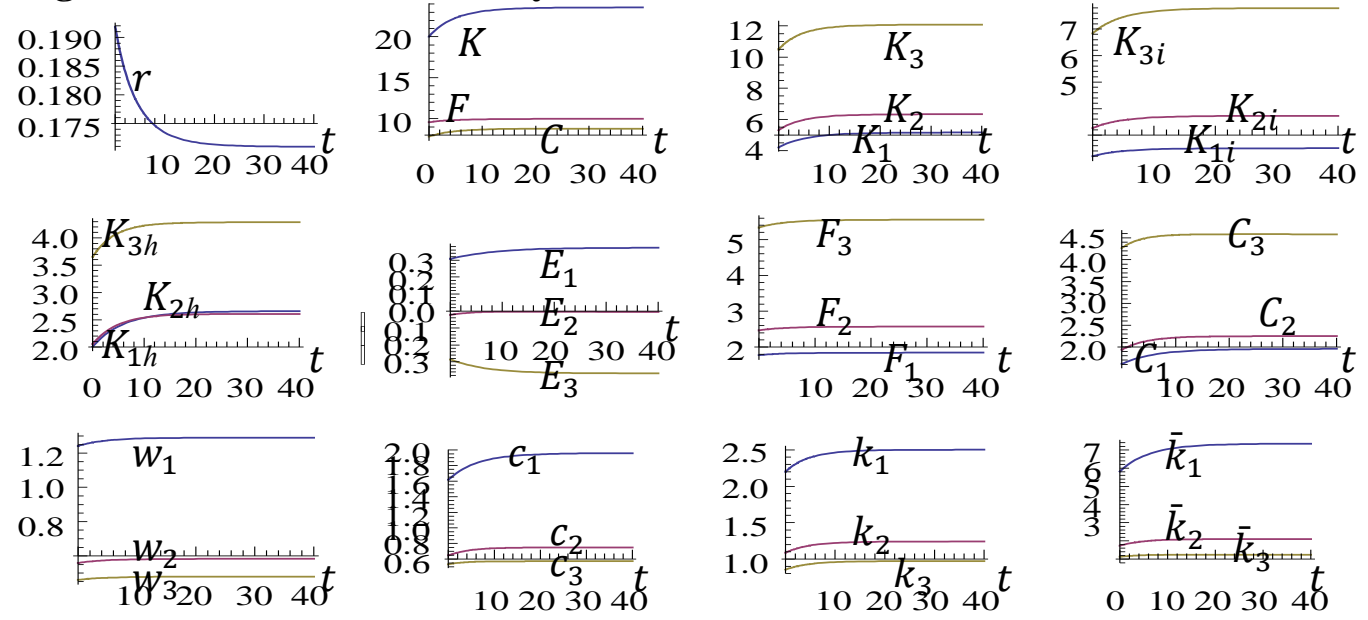

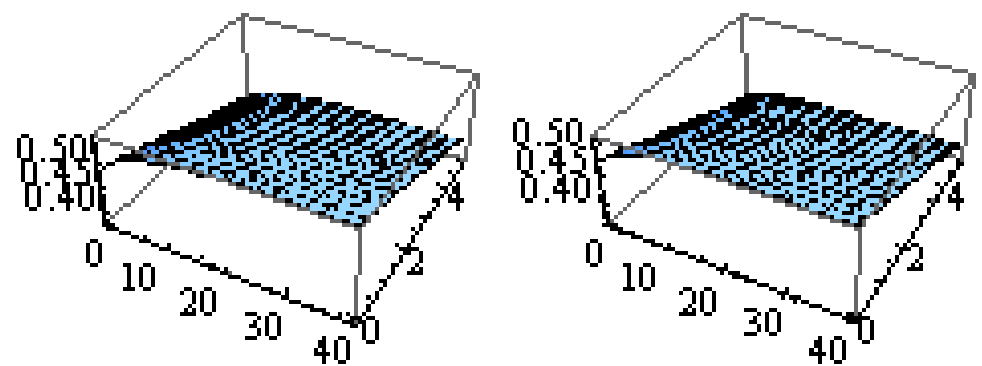

$R_{1 h}\left(\omega_{1}, t\right)$

$R_{1}\left(\omega_{1}, t\right)$

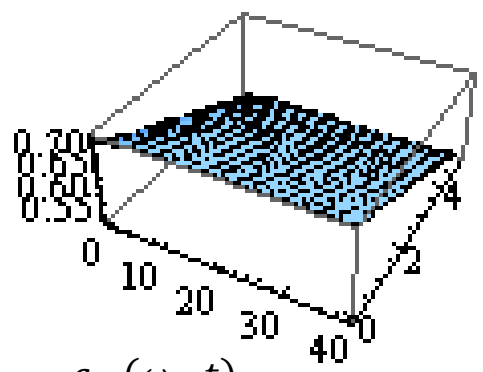

$c_{1 h}\left(\omega_{1}, t\right)$
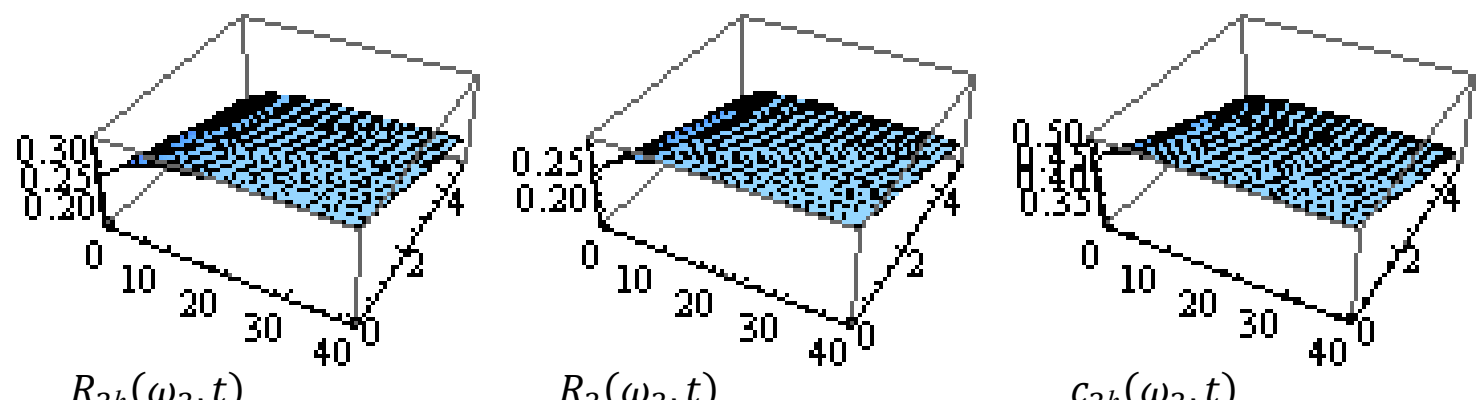

$R_{2 h}\left(\omega_{2}, t\right)$

$R_{2}\left(\omega_{2}, t\right)$

$c_{2 h}\left(\omega_{2}, t\right)$
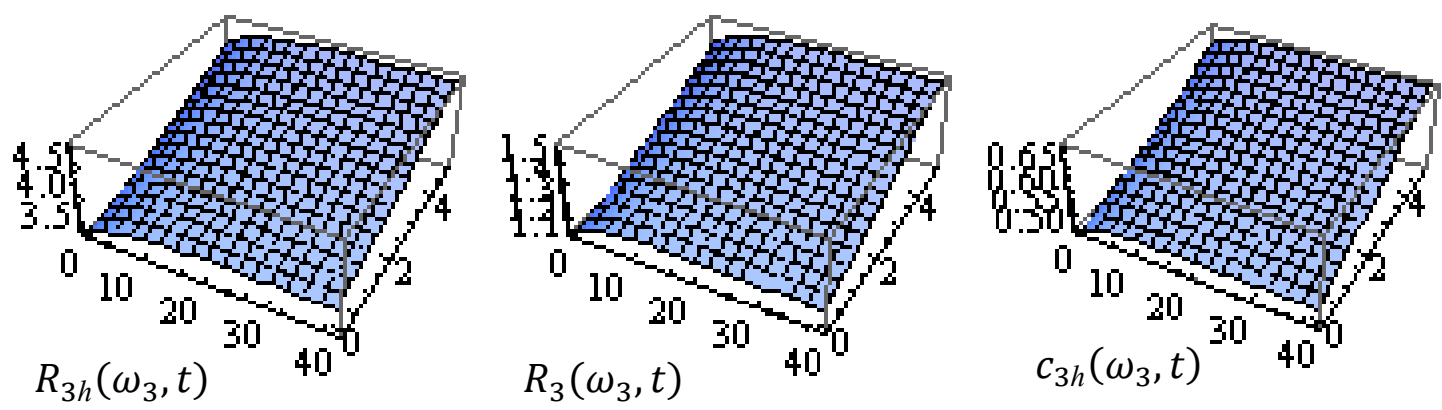

5. Comparative Dynamic Analysis

This section examines effects of changes in some parameters.

\subsection{The developed economy improves its technology}

First, we are interested in effects of the DE's technological change on the global economy. It has been argued that productivity differences explain much of the variation in incomes across countries, and technology plays a key role in determining productivity (e.g., Krugman and Venables, 1995; Manasse and Turrini, 2001; Nakajima, 2003; and Agénor, 2004). The pattern of worldwide technical change is determined largely by international technology diffusion. As 
globalization is deepening, it is important to provide analytical frameworks for analyzing global economic interactions. For instance, it is important to examine how a developing economy like India or China may affect different economies as its technology is improved or population is increased; or how trade patterns may be affected as technologies are further improved or propensities to save are reduced in developed economies like the US or Japan. We now study what will happen to the global economy when the technology of the DE's industrial sector is improved in the following way: $A_{1}: 1.4 \Rightarrow 1.5$. We illustrate the change rates as in Figure 3 . In the plots, a variable $\bar{\Delta} x(t)$ stand for the change rate of the variable $x(t)$ in percentage due to changes in the parameter value. We see that the rate of interest initially rises but finally approaches its previous equilibrium value. Although initially the global output level, consumption and wealth are all reduced, the variables raise over its past values. We find similar changes in the levels of capital stocks employed by the two sectors in each country. The DE's trade balance is deteriorated initially but improved later on. The trade balances o the other two economies change are improved initially but deteriorated late on. The DE's output level is increased, the other two economies' output levels are reduced initially but increased late. The consumption level of the DE is reduced initially but increased later; the consumptions of the other two economies are slightly affected. The wage rate, per consumption level, and per capita wealth in the DE are finally increased; the wage rates, per consumption levels, and per capita wealth levels in the other economies are slightly affected. The land rent, housing rent and level of housing consumption in the DE are increased initially. 
Figure 3 The Developed Economy Improves Its Technology
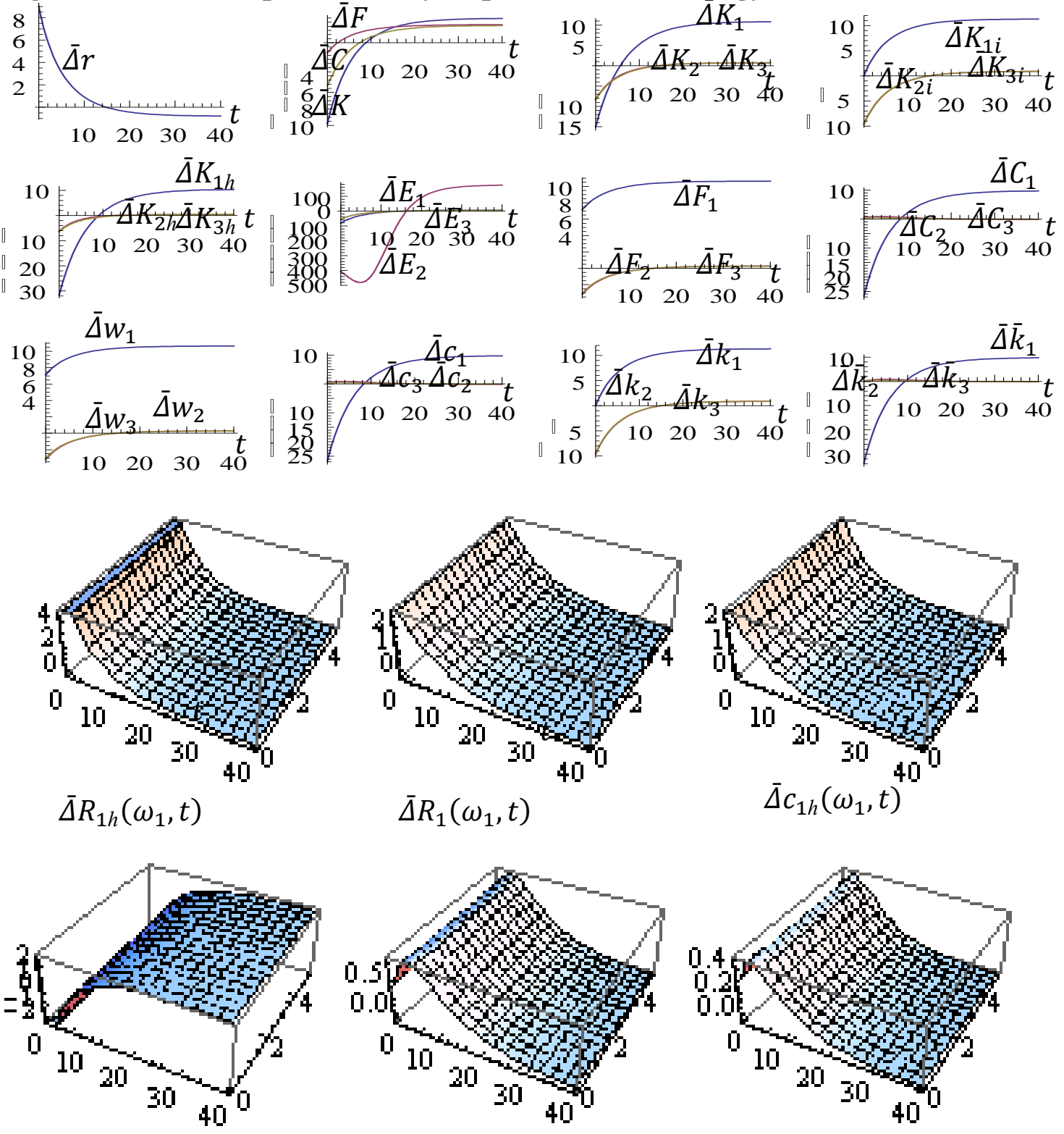

$$
\bar{\Delta} R_{2 h}\left(\omega_{2}, t\right)
$$

$$
\bar{\Delta} R_{2}\left(\omega_{2}, t\right)
$$

$$
\bar{\Delta} c_{2 h}\left(\omega_{2}, t\right)
$$
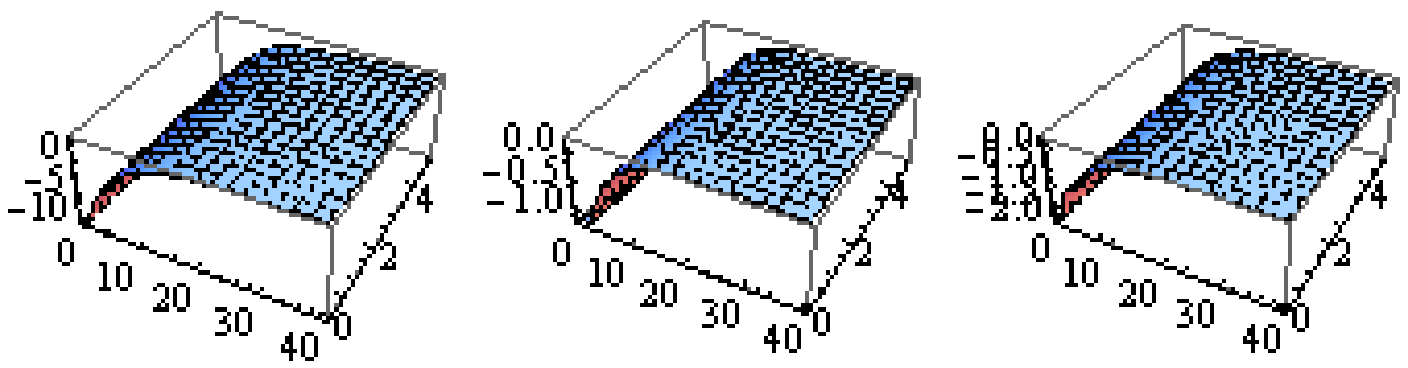

$\bar{\Delta} R_{3 h}\left(\omega_{3}, t\right)$

$\bar{\Delta} R_{3}\left(\omega_{3}, t\right)$

$\bar{\Delta} c_{3 h}\left(\omega_{3}, t\right)$ 


\subsection{The developed economy raises its propensity to save}

We now study what will happen to the global economy when the DE increases its propensity to save in the following way: $\lambda_{01}: 0.75 \Rightarrow 0.8$. As shown in Figure 4, the rate of interest falls over time. As the propensity to save is increased, there is more capital, resulting in the fall of the rate of interest. The global capital stocks and consumption are reduced initially but increased later. The rise of the propensity to save leads to a long-term increase in the global consumption. It is interesting to note that the developed economy which raises its propensity increases its consumption level in the long term, but the other two economies will consume less than before in the long term. The DE's trade balance is slightly improved. The trade balances of the other two economies change are deteriorated. The ID's trade balance is deteriorated much more than the UE. The levels of capital stocks employed by the two sectors in each country are increased in the long term. Each country's output and wage rate are all increased in the long term. The per capita wealth and consumption level in the DE are increased, but the variables in the other two economies are reduced. Hence, the UE and the IE suffer in terms of per capita consumption and per capita wealth. In the DE and IE, the housing consumption, the land rent and housing rent fall. In the UE, the housing consumption, the land rent and housing rent rise.

Figure 4 The Developed Economy Raises Its Propensity to Save
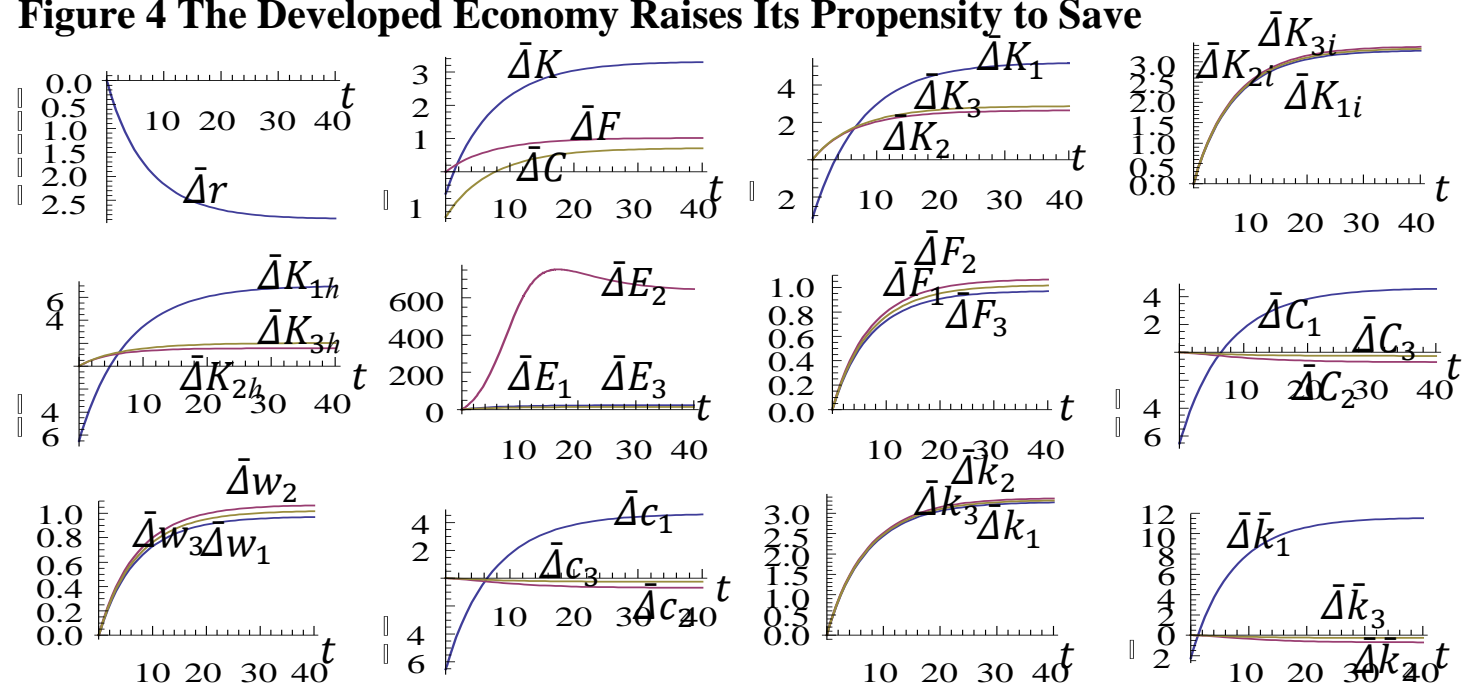

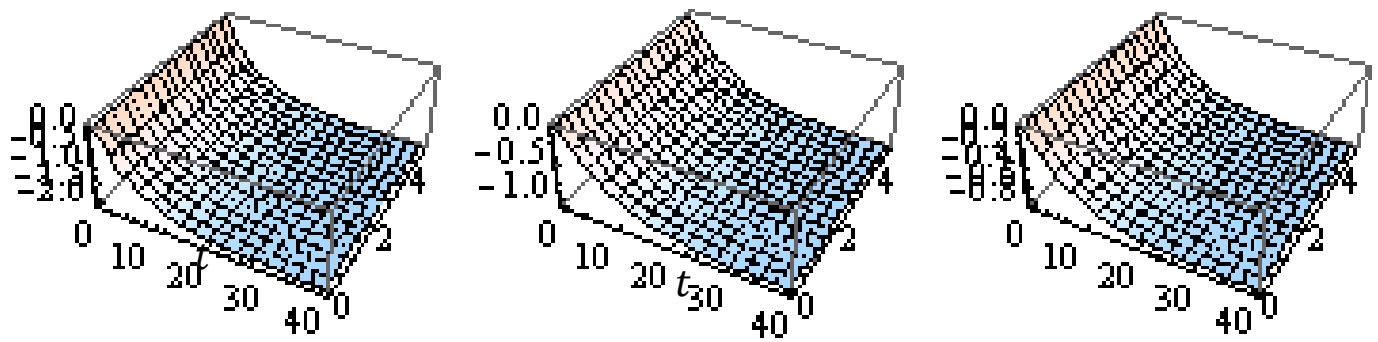

$\bar{\Delta} R_{1 h}\left(\omega_{1}, t\right)$

$\bar{\Delta} R_{1}\left(\omega_{1}, t\right)$

$\bar{\Delta} c_{1 h}\left(\omega_{1}, t\right)$
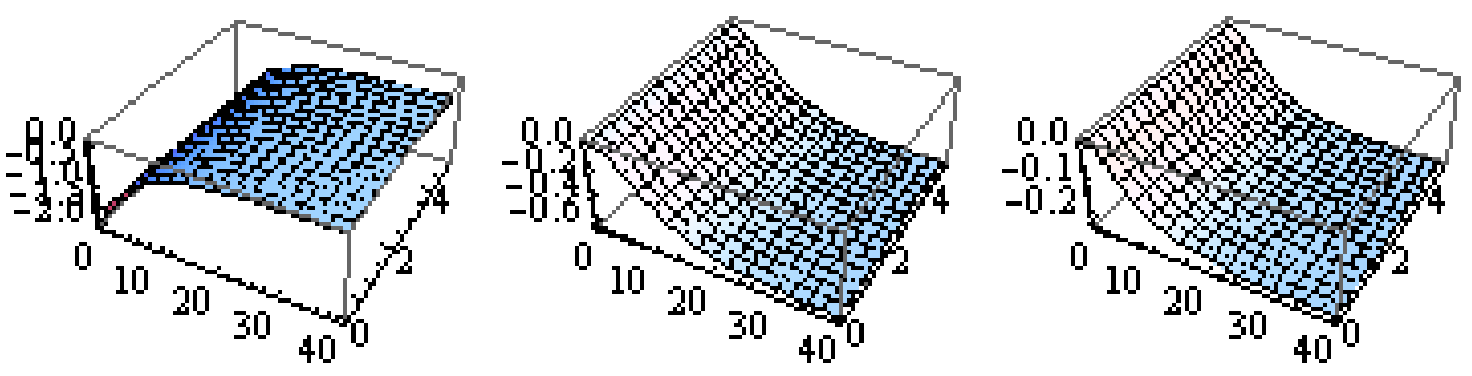

$\bar{\Delta} R_{2 h}\left(\omega_{2}, t\right)$

$\bar{\Delta} R_{2}\left(\omega_{2}, t\right)$

$\bar{\Delta} c_{2 h}\left(\omega_{2}, t\right)$
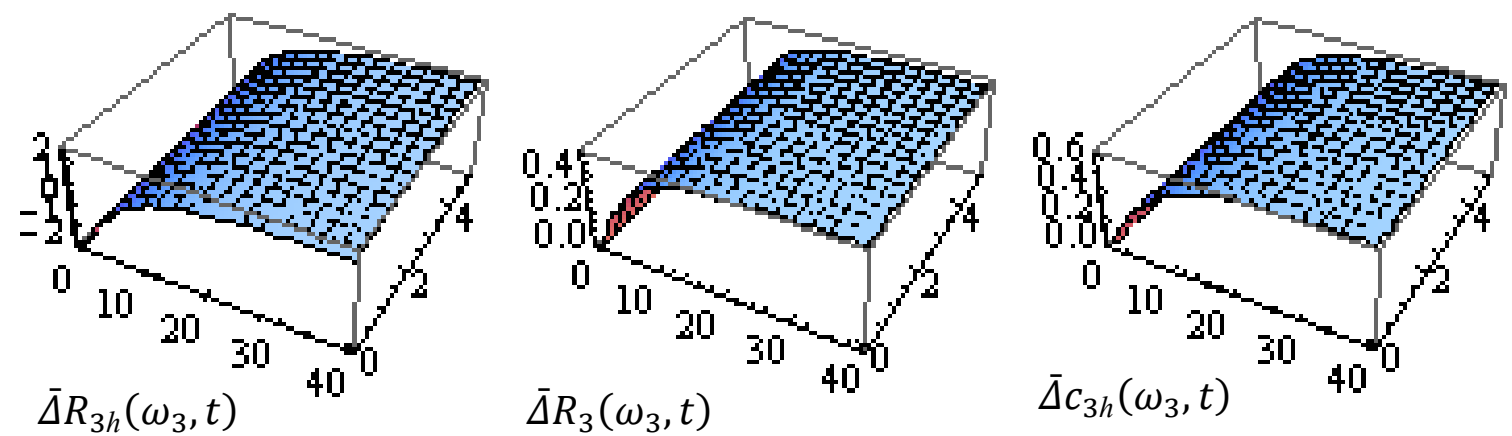

\subsection{The underdeveloped economy has more population}

Another important issue is the impact of population increase in developing economies. We examine this issue by increasing the UE's population in the following way: $N_{3}: 8 \Rightarrow 9$. As shown in Figure 5, the rate of interest falls initially and then rises. The rise of the UE's population increases the global capital, output and consumption. Nevertheless, effects on the three economies vary. The total capital stocks employed by the UE and the capital stocks by the UE's two sectors are all increased; but the total capital stocks employed by the IE and DE and the capital stocks by the two economies' two sectors are initially increased, but reduced in the long term. The UE's consumption and output are increased; but the output levels in the other two economies are 
reduced. The wage rates and capital intensities in the three economies are all reduced. The per capita consumption and wealth levels in the three economies are only slightly affected in the long term. The households in the UD consume less housing due to the population growth; but the households in the other two economies consume more housing.

\section{Figure 5 The Underdeveloped Economy Has More Population}
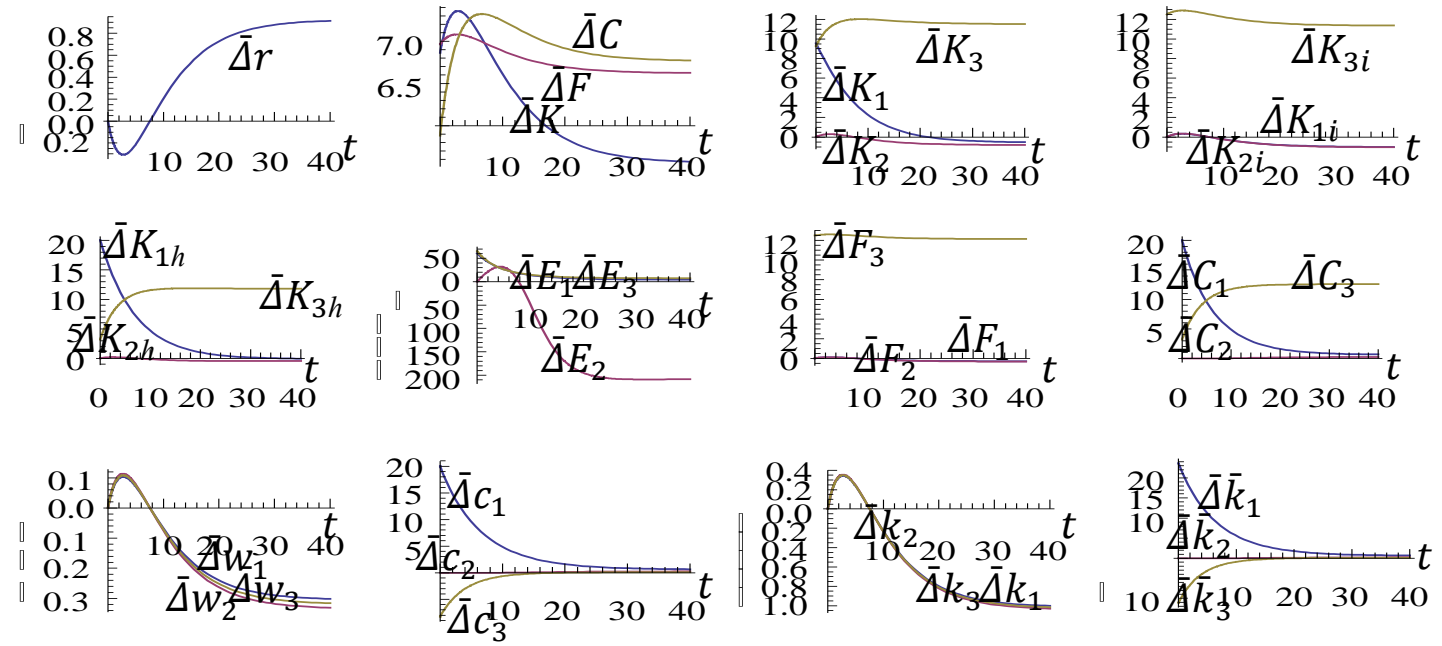

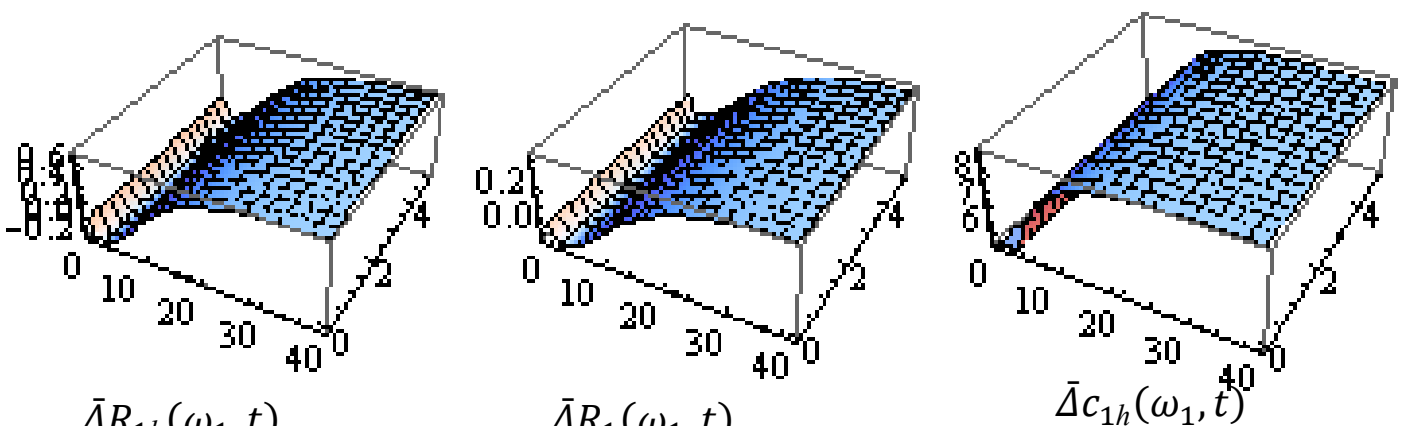

$$
\bar{\Delta} R_{1 h}\left(\omega_{1}, t\right)
$$

$$
\bar{\Delta} R_{1}\left(\omega_{1}, t\right)
$$
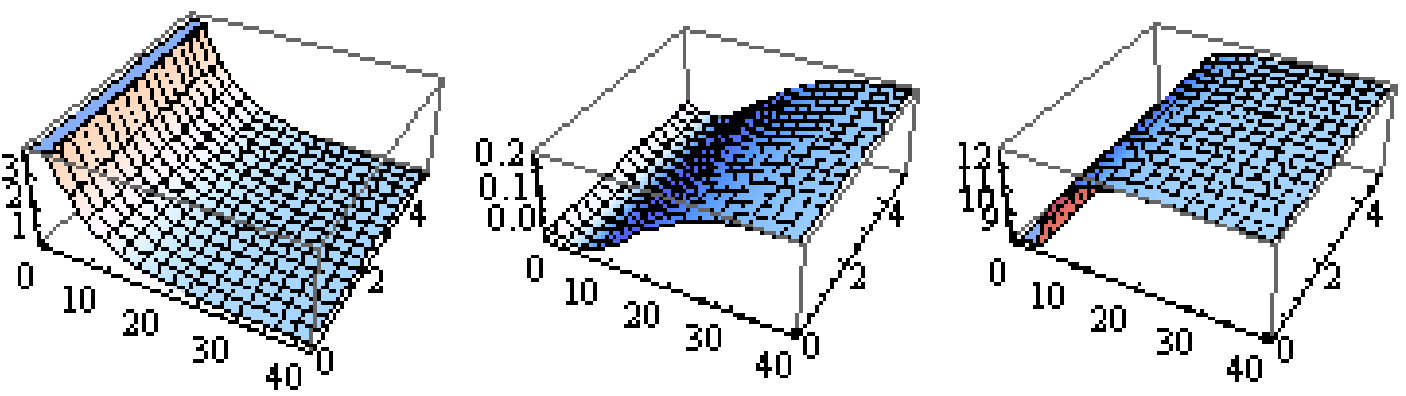

$\bar{\Delta} R_{2 h}\left(\omega_{2}, t\right)$

$\bar{\Delta} R_{2}\left(\omega_{2}, t\right)$
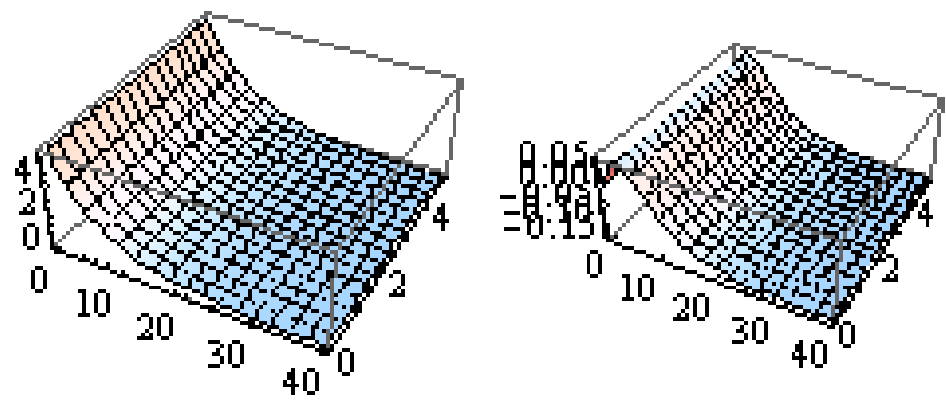

$\bar{\Delta} R_{3}\left(\omega_{3}, t\right)$

$\bar{\Delta} R_{3 h}\left(\omega_{3}, t\right)$

\section{Concluding Remarks}

This study examined dynamic interactions among economic growth, housing markets, residential distribution and international trade. As shown by Wheaton (2004), in US cities actual employment is almost as dispersed as residences. Land should have "mixed" rather than exclusive use in general. Nevertheless, it is still a very challenging question in economics to explicitly introduce housing markets into international growth models with microeconomic foundations. The paper built a multi-country growth model with economic geography and capital accumulation. The unique feature is to introduce economic geography and housing markets into multi-country growth model with microeconomic foundations. The model integrates the four well-known key models - 
the Solow growth model, the Oniki-Uzawa trade model, the Alonso urban model, and the Muth housing model - in growth theory, international growth economics and urban economics within a comprehensive framework. We showed that the dynamics of the $J$-country world economy can be described by $J$ differential equations. Then, we simulated the global economy with three countries, respectively called developed, industrializing, and developing economy. It was demonstrated that when the production functions take on the Cobb-Douglas form and the parameters are properly specified, the world dynamics has a unique equilibrium. We also carried out comparative dynamic analysis with regard to productivity levels, propensities to save, and the population of the three economies. The simulation results demonstrate that, for instance, as the developed economy's population increases, the per-capita consumption levels, per-capita wealth and wage rates in the three economies are increased in the long term; but these variables are reduced as the developing economy's population rises. It was shown that as the industrializing economy's productivity is improved, the developing economy suffers in the sense that the perwork-time output level, the wage rate, the per-capita wealth, the leisure time, the per consumption level and the share of the global output of the developing economy are all reduced.

The Solow model is the key model in the neoclassical economic growth theory and the Oniki-Uzawa growth model is the key model of global economic dynamics with capital accumulation. The Alonso model and Muth housing model are the key models in the modern urban economics. The paper has its merit in that it synthesizes the four models in the growth theory, trade theory and urban economics in a compact framework. Although we claimed to integrate the four key models in economics, we have limited our study to an extremely simplified spatial structure of the economic system. Many limitations of this model become apparent in the light of the sophistication of the literature of growth theory, international economics, and regional science and urban economics. We may extend our model on the basis of the contemporary literature of economics. Numerous meaningful extensions of either of these models have already existed (e.g., Fujita and Thisse, 2002; Forslid and Ottaviano, 2003; Henderson and Thisse, 2004; and RobertNicound, 2005). We may introduce more realistic representations of housing market dynamics and transportation systems with congestion. To explain urban configuration, we may take account of communications among firms as by Borukov and Hochman (1977) and O'Hara (1977). For instance, we may consider that firms use floor space and interact among themselves and they have 
to bear transaction costs. Within the framework proposed in this study, we can explain, at least in principle, spatial configuration of the CBD over time. As shown in Fujita and Thisse (2002: Chap. 6) by combining the basic ideas by Beckmann and Borukov and Hochman mentioned above, various urban forms can be explained due to communication externalities. See also Imai (1982), Lucas and Rossi-Hansberg (2002), and Berliant et al. (2002) for this direction of research. Another extension is in the area of housing taxation. Trade economists have recently developed different trade models in which endogenous growth is generated either by the development of new varieties of intermediate or final goods or by the improvement of an existing set of goods with endogenous technologies (e.g., Chari and Hopenhayn, 1991; Martin and Ottaviano, 2001; Brecher et al., 2002; Nocco, 2005; Lee, 2011; and Hashmi, 2013).

\section{Appendix: Proving Lemma 1 and Determining Equilibrium}

First, we define the total disposal income as:

$\hat{Y}_{j}(t) \equiv \int_{0}^{L_{j}} \hat{y}_{j}\left(\omega_{j}, t\right) n_{j}\left(\omega_{j}, t\right) d \omega_{j}$

Multiplying all the equations in $(10)$ by $n_{j}\left(\omega_{j}, t\right)$ and then integrating the resulted equations from 0 to $L_{j}$ with respect to $\omega_{j}$, we obtain:

$C_{j}=\xi_{j} \hat{Y}_{j},\left(r+\delta_{k}\right) \frac{K_{j h}}{\alpha_{j h}}=\eta_{j} \hat{Y}_{j}, S_{j}=\lambda_{j} \hat{Y}_{j},(A 1)$

where we use $R_{j h} c_{j h}=\left(r+\delta_{k}\right) k_{j h} / \alpha_{j h}$ from equations (3). From $r+\delta_{k j}=A_{j} \alpha_{j} k_{j}^{-\beta_{j}}$ in (1) and $\left(r+\delta_{k j}\right) K_{j h}=\alpha_{j h} \eta_{j} \hat{Y}_{j}$ from (A1), we have:

$\frac{\alpha_{j h} \eta_{j} \hat{Y}_{j}}{K_{j h}}=A_{j} \alpha_{j} k_{j}^{-\beta_{j}}$

From (3) and (10), we have $R_{j}=\beta_{j h} \eta_{j} n_{j} \hat{y}_{j}$. Integrating $R_{j}=\beta_{j h} \eta_{j} n_{j} \hat{y}_{j}$ from 0 to $L_{j}$ with respect to $\omega_{j}$, we obtain:

$\bar{R}_{j}=\beta_{j h} \eta_{j} \hat{Y}_{j} .(\mathrm{A} 3)$ 
From (6) and (7), we have:

$\hat{Y}_{j}=(1+r) \bar{K}_{j}+w_{j} N_{j}+\bar{R}_{j} \cdot(\mathrm{A} 4)$

Insert (A3) into (A.4)

$\widehat{Y}_{j}=\frac{(1+r) \bar{K}_{j}+w_{j} N_{j}}{1-\beta_{j h} \eta_{j}}$

From (A2) and (A5), we solve:

$K_{j h}=(1+r) \tilde{\eta}_{j} k_{j}^{\beta_{j}} \bar{K}_{j}+\tilde{\eta}_{j} w_{j} k_{j}^{\beta_{j}} N_{j},(\mathrm{~A} 6)$

where

$\tilde{\eta}_{j}=\frac{\alpha_{j h} \eta_{j}}{A_{j} \alpha_{j}\left(1-\beta_{j h} \eta_{j}\right)}$

From (A6) and $K_{j}=K_{j h}+K_{j i}$, we have:

$K_{j}=(1+r) \tilde{\eta}_{j} k_{j}^{\beta_{j}} \bar{K}_{j}+\left(\tilde{\eta}_{j} A_{j} \beta_{j}+1\right) k_{j} N_{j},(\mathrm{~A} 7)$

where we use $K_{j i}=k_{j} N_{j}$ and $w_{j}=A_{j} \beta_{j} k_{j}^{\alpha_{j}}$. From (1) we obtain:

$k_{j}=\varphi_{j}\left(k_{1}\right) \equiv\left(\frac{A_{j} \alpha_{j}}{A_{1} \alpha_{1} k_{1}^{-\beta_{1}}+\delta_{j}}\right)^{\frac{1}{\beta_{j}}}, j=1, \ldots, J$, (A8)

where $\delta_{j} \equiv \delta_{k 1}-\delta_{k j}$. It should be noted that $\varphi_{1}=k_{1}$. From equations (1) and (A8), we determine the wage rates as functions of $k_{1}$ as follows:

$r=\bar{\varphi}\left(k_{1}\right) \equiv A_{1} \alpha_{1} k_{1}^{-\beta_{1}}-\delta_{k 1}, w_{j}=\bar{\varphi}_{j}\left(k_{1}\right) \equiv A_{j} \beta_{j} \varphi_{j}^{\alpha_{j}}\left(k_{1}\right), j=1, \cdots, J$. (A9)

From (A6) and (A7) it is straightforward to see that $K_{j}$ and $K_{j h}$ can now be considered as functions of $k_{1}$ and $\left(\bar{K}_{j}\right)$. Substituting (A7) into (15) yields: 


$$
\begin{aligned}
& \bar{K}_{1}=\Lambda\left(k_{1},\left\{\bar{K}_{j}\right\}\right) \\
& \equiv\left\{\sum_{j=2}^{J}\left[1-(1+r) \tilde{\eta}_{j} k_{j}^{\beta_{j}}\right] \bar{K}_{j}-\sum_{j=1}^{J}\left(\tilde{\eta}_{j} A_{j} \beta_{j}+1\right) k_{j} N_{j}\right\} \frac{1}{(1+r) \tilde{\eta}_{1} k_{1}^{\beta_{1}}-1},
\end{aligned}
$$

where $\left\{\bar{K}_{j}\right\} \equiv\left\{\bar{K}_{2}, \ldots, \bar{K}_{J}\right\}$. Equation (A10) shows that $\bar{K}_{1}$ can now be considered as functions of $k_{1}$ and $\left\{\bar{K}_{j}\right\}$. It is straightforward to check that $\bar{K}_{1}, r, w_{j}, K_{j i}, F_{j}, \widehat{Y}_{j}, \bar{R}_{j}, \bar{r}_{j}, K_{j}$ and $K_{j h}$ can treated as functions of $J$ variables, $k_{1}$ and $\left\{\bar{K}_{j}\right\}$.

We now show that the residential density distribution is invariant in time. That is, $d n_{j} / d t=0$ for the given technologies, preference and transportation system. By the definition of $\hat{y}_{j}\left(\omega_{j}, t\right)$, we have:

$\hat{y}_{j}\left(\omega_{j}\right)=(1+r) \bar{k}_{j}\left(\omega_{j}\right)+w_{j}+\bar{r}_{j} .(\mathrm{A} 11)$

Insert this equation into equation (11)

$$
\dot{\bar{k}}_{j}\left(\omega_{j}\right)=\left(\lambda_{j}-1+\lambda_{j} r\left(k_{1}\right)\right) \bar{k}_{j}\left(\omega_{j}\right)+\lambda_{j}\left[w_{j}\left(k_{1}\right)+\bar{r}_{j}\left(k_{1},\left\{\bar{K}_{j}\right\}\right)\right], 0 \leq \omega_{j} \leq L_{j},(\mathrm{~A} 12)
$$

where we use $s_{j}\left(\omega_{j}\right)=\lambda_{j} \hat{y}_{j}\left(\omega_{j}\right)$. This is a linear differential equation in $k_{j}\left(\omega_{j}, t\right)$. For convenience of expression, we rewrite equation (A12) as

$$
\dot{\bar{k}}_{j}\left(\omega_{j}, t\right)+h_{1 j}(t) \bar{k}_{j}\left(\omega_{j}, t\right)=h_{2 j}(t), 0 \leq \omega_{j} \leq L_{j},(\mathrm{~A} 13)
$$

where

$$
h_{1 j}(t) \equiv 1-\lambda_{j}-\lambda_{j} r_{j}\left(k_{1}(t)\right), h_{2 j}(t) \equiv \lambda_{j}\left[w_{j}\left(k_{1}(t)\right)+\bar{r}_{j}\left(k_{1}(t),\left\{\bar{K}_{j}(t)\right\}\right)\right], 0 \leq \omega \leq L .
$$

Applying the general solution for this type of linear differential equations, we get:

$$
\bar{k}_{j}\left(\omega_{j}, t\right)=e^{-\int h_{1 j}(\tau) d \tau}\left[h_{0 j}+\int h_{2 j}(\tau) e^{\int h_{1 j}(\tau) d \tau} d \tau\right]
$$

where $h_{0 j}$ are constants to be determined by initial conditions. Equation (A14) tells that the path of any household's wealth over time and space is given as a function of functions of $J$ variables, $k_{1}$ and $\left\{\bar{K}_{j}\right\} \equiv\left\{\bar{K}_{2}, \ldots, \bar{K}_{J}\right\}$. From equation (A12), as $h_{1 j}$ and $h_{2 j}$ are independent of location, 
we see that if the initial distribution of the wealth is not dependent on location (i.e., $k(\omega, 0)=$ $K(0) / N), h_{0 j}$ is also independent of location. From equation (A14), we conclude that $\bar{k}_{j}\left(\omega_{j}, t\right)$ is independent of location, that is

$\bar{k}_{j}\left(\omega_{j 1}\right)=\bar{k}_{j}\left(\omega_{j 2}\right), 0 \leq \omega_{j 1}, \omega_{j 2} \leq L_{j}$.

In this study, we assume that the initial wealth distribution is independent of location, $\omega_{j}$, We thus have $\bar{k}_{j}(t)=\bar{K}_{j}(t) / N_{j}$.

By this property and equations (A11), we have $\hat{y}_{j}\left(\omega_{j 1}\right)=\hat{y}_{j}\left(\omega_{j 2}\right), 0 \leq \omega_{j 1}, \omega_{j 2} \leq L_{j}$. As shown later on, this property greatly simplifies our analysis. This is the technical reason that we omit transportation costs in this model. If we introduce transportation costs as a function of the distance to the $\mathrm{CBD}$, then the distance variable $\omega_{j}$, will appear in $h_{2 j}$. It can be seen that the wealth distribution is dependent on $\omega_{j}$. For the analytical tractability, we take account of distance in the residential location through the time distribution between leisure and travel. We have shown that the per-capita wealth and disposal income are invariant in space but changeable over time. We now show that the residential density distribution is invariant in time but changeable over space.

Substituting equations (10) into $U_{j}\left(\omega_{j}, t\right)$ in (9) and then using $U_{j}(0)=U_{j}\left(\omega_{j}\right)$, we have:

$\frac{R_{j h}\left(\omega_{j}\right)}{R_{j h}(0)}=\left(\frac{n_{j}\left(\omega_{j}\right)}{n_{j}(0)}\right)^{\mu_{j} / \eta_{j}}\left(\frac{T_{j h}(\omega)}{T_{j h}(0)}\right)^{\sigma_{j} / \eta_{j}}$,

where we use $\hat{y}_{j}(0)=\hat{y}_{j}\left(\omega_{j}\right)$. From $R_{j h}\left(\omega_{j}\right) c_{j h}\left(\omega_{j}\right)=\eta_{j} \hat{y}_{j}\left(\omega_{j}\right)$ and $\left(r+\delta_{k}\right) k_{j h}=$ $\alpha_{j h} R_{j h} c_{j h}$, we have:

$k_{j h}\left(\omega_{j}\right)=\frac{\alpha_{j h} \eta_{j} \hat{y}_{j}}{r+\delta_{k}}$

Substituting $c_{j h}=A_{j h} k_{j h}^{\alpha_{j h}} L_{j h}^{\beta_{j h}}$ into $\left(r+\delta_{k}\right) k_{j h}=\alpha_{j h} c_{j h} R_{j h}$, we have:

$R_{j h}\left(\omega_{j}\right)=\frac{\eta_{j}^{\beta_{j h}}}{A_{j h}}\left(\frac{r+\delta_{k}}{\alpha_{j h}}\right)^{\alpha_{j h}} n_{j}^{\beta_{j h}}\left(\omega_{j}\right) \hat{y}_{j}^{\beta_{h}}$

Substitute equation (A17) into equation (A15) 
$n_{j}\left(\omega_{j}\right)=n_{j}(0)\left(\frac{T_{j h}\left(\omega_{j}\right)}{T_{j h}(0)}\right)^{\beta_{0 j}}$

where $\beta_{0 j} \equiv \sigma_{j} /\left(\eta_{j} \beta_{j h}-\mu_{j}\right)$. Integrating equation (A18), we obtain:

$n_{j}(0, t)=\frac{N_{j} T_{j h}^{\beta_{0 j}}(0)}{\int_{0}^{L_{j}} T_{j h}^{\beta_{0 j}}\left(\omega_{j}\right) d \omega_{j}}$

As $T_{j h}\left(\omega_{j}\right)$ is explicitly defined as a function of location and independent of time, we see that $n_{j}(0, t)$ is independent of time. By equation (A18), we conclude that $n(\omega, t)$ is independent of time but dependent on location. This property is important for us to find differential equations for $k_{1}$ and $\left\{\bar{K}_{j}\right\}$.

Multiplying the two sides of (A12) by $n_{j}\left(\omega_{j}\right)$ and then integrating the resulted equations from 0 to $L_{j}$, we obtain:

$$
\begin{aligned}
& \dot{\bar{K}}_{1}=\Lambda\left(k_{1},\left\{\bar{K}_{j}\right\}\right) \equiv\left(\lambda_{1}-1+\lambda_{1} r\left(k_{1}\right)\right) \bar{K}_{1}+\lambda_{1} N_{1}\left[w_{1}\left(k_{1}\right)+\bar{r}_{1}\left(k_{1},\left\{\bar{K}_{j}\right\}\right)\right],(\mathrm{A} 20) \\
& \dot{\bar{K}}_{j}=\Lambda_{j}\left(k_{1},\left\{\bar{K}_{j}\right\}\right) \equiv\left(\lambda_{j}-1+\lambda_{j} r\left(k_{1}\right)\right) \bar{K}_{j}+\lambda_{j} N_{j}\left[w_{j}\left(k_{1}\right)+\bar{r}_{j}\left(k_{1},\left\{\bar{K}_{j}\right\}\right)\right],(A 21)
\end{aligned}
$$

where we use

$$
\dot{\bar{K}}_{j}(t)=\int_{0}^{L_{j}} \frac{d\left(\bar{k}_{j}\left(\omega_{j}, t\right) n_{j}\left(\omega_{j}, t\right)\right)}{d t} d \omega_{j}=\int_{0}^{L_{j}} \dot{\bar{k}}_{j}\left(\omega_{j}, t\right) n_{j}\left(\omega_{j}, t\right) d \omega_{j}, j=2, \ldots, J
$$

in which we use $\dot{n}_{j}=0$. Taking derivatives of (A10) in $t$, we have:

$$
\dot{\bar{K}}_{1}=\frac{\partial \Lambda}{\partial k_{1}} \dot{k}_{1}+\sum_{j=2}^{J} \Lambda_{j} \frac{\partial \Lambda}{\partial \bar{K}_{j}},(\mathrm{~A} 22)
$$

where we also use (A21). From (A20) and (A21), we solve:

$$
\dot{k}_{1}=\Lambda_{1}\left(k_{1},\left\{\bar{K}_{j}\right\}\right)
$$


$\equiv\left\{\left(\lambda_{1}-1+\lambda_{1} r\left(k_{1}\right)\right) \bar{K}_{1}+\lambda_{1} N_{1}\left[w_{1}\left(k_{1}\right)+\bar{r}_{1}\left(k_{1},\left\{\bar{K}_{j}\right\}\right)\right]-\sum_{j=2}^{J} \Lambda_{j} \frac{\partial \Lambda}{\partial \bar{K}_{j}}\right\}\left(\frac{\partial \Lambda}{\partial k_{1}}\right)^{-1}$

From (A21) and (A23), we have thus $J$ differential equations which contain $J$ variable, $k_{1}$ and $\left\{\bar{K}_{j}\right\}$. We have thus proved the Lemma.

We now determine how to determine an equilibrium point. At equilibrium from (A20) and (A21) we have:

$$
\left(\lambda_{j}-1+\lambda_{j} r\left(k_{1}\right)\right) \bar{K}_{j}+\lambda_{j} N_{j}\left[w_{j}\left(k_{1}\right)+\bar{r}\left(k_{1},\left\{\bar{K}_{j}\right\}\right)\right]=0, j=1, \ldots, J .(A 24)
$$

From (A3) and (A5), we have:

$$
\bar{r}_{j}=\left[\frac{(1+r) \bar{K}_{j}+w_{j} N_{j}}{1-\beta_{j h} \eta_{j}}\right] \frac{\beta_{j h} \eta_{j}}{N_{j}}
$$

Insert (A25) in (A24)

$$
\bar{K}_{j}=\frac{\lambda_{j} w_{j} N_{j}}{1-\beta_{j h} \eta_{j}}\left[1-\lambda_{j}-\lambda_{j} r-\frac{(1+r) \lambda_{j} \beta_{j h} \eta_{j}}{1-\beta_{j h} \eta_{j}}\right]^{-1}, j=1, \ldots, J
$$

Inserting (A26) and (A7) in (15), we have:

$$
\begin{aligned}
& \Omega\left(k_{1}\right)=\sum_{j=1}^{J}\left(\tilde{\eta}_{j} A_{j} \beta_{j}+1\right) k_{j} N_{j}- \\
& \sum_{j=1}^{J}\left(1-(1+r) \tilde{\eta}_{j} k_{j}^{\beta_{j}}\right) \frac{\lambda_{j} w_{j} N_{j}}{1-\beta_{j h} \eta_{j}}\left[1-\lambda_{j}-\lambda_{j} r-\frac{(1+r) \lambda_{j} \beta_{j h} \eta_{j}}{1-\beta_{j h} \eta_{j}}\right]^{-1}=0 .
\end{aligned}
$$

Equation (27) contains a single variable, $k_{1}$. Once we solve $k_{1}$, we can directly calculate $\bar{K}_{j}$. Then following the Lemma, we determine the values of all the other variables in the global economy. 


\section{References}

Abel, A., Bernanke, B.S., and Croushore, D. (2007) Macroeconomics. New Jersey: Prentice Hall.

Abdel-Rahman, H.M. (2004) The City System Paradigm: New Frontiers, in Urban Dynamics and Growth: Advances in Urban Economics, edited by Capello, R. and Nijkamp, P. Amsterdam: Elsevier.

Agénor, P.R. (2004) Does Globalization Hurt the Poor? International Economics and Economic Policy 1, 21-51.

Alonso, W. (1964) Location and Land Use. MA., Cambridge: Harvard University Press.

Anas, A. (1978) Dynamics of Urban Residential Growth. Journal of Urban Economics 5, 66-87.

Anas, A. (1982) Dynamics of Urban Residential Growth. Journal of Urban Economics 5, 66-87.

Anas, A. (1990) Taste Heterogeneity and Urban Spatial Structure: The Logit Model and Monocentric Theory Reconciled. Journal of Urban Economics 28, 318-35.

Arnott, R.J. (1980) A Simple Urban Growth Model with Durable Housing. Regional Science and Urban Economics 10, 53-76.

Arnott, R. J. (1987) Economic Theory and Housing, in Handbook of Regional and Urban Economics, Volume II, edited by Mills, E.S. Amsterdam: North-Holland

Arnott, R., Braid, R., Davidson, R. and Pines, D. (1999) A General Equilibrium Spatial Model of Housing Quality and Quantity. Regional Science and Urban Economics 29, 283-316.

Baldwin, R.E. and Martin, P. (2004) Agglomeration and Regional Growth, in Handbook of Regional and Urban Economics, Vol. 4, edited by J.V. Hendersson and J.F. Thisse. Amsterdam: Elsevier.

Beckmann, M.J. (1969) On the Distribution of Urban Rent and Residential Density. Journal of Economic Theory 1, 60-7.

Beckmann, M.J. (1976) Spatial Equilibrium in the Dispersed City, in Mathematical Land Use Theory, edited by Papageorgiou, Y.Y, 117-25. MA., Lexington: Lexington Books.

Beckmann, M.J. and Papageorgiou, Y.Y. (1989) Heterogeneous Tastes and Residential Location. Journal of Regional Science 29, 317-23.

Berliant, M., Peng, S.K. and Wang, P. (2002) Production Externalities and Urban Configuration. Journal of Economic Theory 104, 275-303. 
Bhagwati, J.N. (1991, edited) International Trade - Selected Readings, second edition. Mass., Cambridge: The MIT Press.

Borukhov, E. and Hochman, O. (1977) Optimum and Market Equilibrium in a Model of a City Without a Predetermined Center. Environment and Planning A 9, 849-56.

Braid, R.M. (2001) Spatial Growth and Redevelopment with Perfect Foresight and Durable Housing. Journal of Urban Economics 49, 425-52.

Brecher, R.A., Chen, Z.Q. and Choudhri, E.U. (2002) Absolute and Comparative Advantage, Reconsidered: The Pattern of International Trade with Optimal Saving. Review of International Economics, 10, 645-656.

Brito, P.M.B. and Pereira, A.M. (2002) Housing and Endogenous Long-Term Growth. Journal of Urban Economics 51, 246-71.

Brueckner, J.K. (1981) A Dynamic Model of Housing Production. Journal of Urban Economics $10,1-14$.

Brueckner, J.K. and Pereira, A.M. (1994) Housing Ownership and the Business Cycle. Journal of Housing Economics 3, 165-85.

Burmeister, E. and Dobell, A.R. (1970) Mathematical Theories of Economic Growth. London: Collier Macmillan Publishers.

Capello, R. and Nijkamp, P. (2004, edited) Urban Dynamics and Growth: Advances in Urban Economics. Amsterdam: Elsevier.

Chari, V.V. and Hopenhayn, H. (1991) Vintage Human Capital, Growth, and the Diffusion of New Technology. The Journal of Political Economy 99, 1142-65.

DiPasquale, D. and Wheaton, W.C. (1996) Urban Economics and Real Estate Markets. Englewood Cliffs: Prentice Hall.

Ethier, W.J. and Svensson, L.E.O. (1986) The Theorems of International Trade with Factor Mobility. Journal of International Economics 20, 21-42.

Findlay, R. (1984) Growth and Development in Trade Models. In Jones, R.W., Kenen, R.B. (Eds.): Handbook of International Economics. Amsterdam: North-Holland.

Forslid, R. and Ottaviano, G.I.P. (2003) An Analytically Solvable Core-Periphery Model. Journal of Economic Geography 3, 229-40.

Frenkel, J.A. and Razin, A. (1987) Fiscal Policy and the World Economy. MA., Cambridge: MIT Press. 
Fujita, M. (1999) Urban Economic Theory - Land Use and City Size. Cambridge: Cambridge University Press.

Fujita, M. and Thisse, J.F. (2002) Economics of Agglomeration: Cities, Industrial Location, and Regional Growth. Cambridge: Cambridge University Press.

Glaeser, E.L. and Gyourko, J. (2005) Urban Decline and Durable Housing. Journal of Political Economy 113, 345-75.

Glaeser, E.L., Kolko, J., and Saiz, A. (2001) Consumer City. Journal of Economic Geography 1, 27-50.

Hashmi, A.R. (2013) Intangible Capital and International Income Differences. Macroeconomic Dynamics 17, 621-45.

Henderson, J.V. (1974) The Sizes and Types of Cities. American Economic Review 64, 640-56.

Henderson, J.V. (1985) Economic Theories and Cities. New York: Academic Press.

Henderson, J.V., Schalizi, Z. and Venables, A.J. (2001) Geography and Development. Journal of Economic Geography 1, 81-105.

Henderson, J.V. and Thisse, J.F. (2004, Eds.) Handbook of Regional and Urban Economics. Amsterdam: Elsevier.

Hockman, O. and Pines, D. (1980) Costs of Adjustment and the Spatial Pattern of a Growing Open City. Econometrica 50, 1371-89.

Ikeda, S. and Ono, Y. (1992) Macroeconomic Dynamics in a Multi-Country Economy - A Dynamic Optimization Approach. International Economic Review 33, 629-644.

Imai, H. (1982) CBD Hypothesis and Economies of Agglomeration. Journal of Economic Theory 28, 275-99.

Jensen, B.S. (1994) The Dynamic Systems of Basic Economic Growth Models. Dordrecht: Kluwer Academic.

Jensen, B.S. and Wong, K.Y. (Eds.) (1998) Dynamics, Economic Growth, and International Trade. Ann Arbor: The University of Michigan Press.

Johnson, H.G. (1971) Trade and Growth: A Geometric Exposition. Journal of International Economics 1, 83-101.

Kanemoto, Y. (1980) Theories of Urban Externalities. Amsterdam: North-Holland.

Kemp, M.C. (1961) Foreign Investment and National Advantage. Economic Record 28, 56-62. 
Krugman, P. and Venables, A.J. (1995) Globalization and the Inequality. Quarterly Journal of Economics 110, 857-80.

Lee, S.F. (2011) Tariff, Growth, and Welfare. Review of International Economics 19, 260-76.

Lin, C.C., Mai, C.C. and Wang, P. (2004) Urban Land Policy and Hosing in an Endogenously Growing Monocentric City. Regional Science and Urban Economics 34, 241-61.

Lucas, R.E. (1988) On the Mechanics of Economic Development. Journal of Monetary Economics 22, 3-42.

Lucas, R.E. and Rossi-Hansberg, E. (2002) On the Internal Structure of Cities. Econometrica 70, 1445-76.

MacDougall, G.D.A. (1960) The Benefits and Costs of Private Investment from Abroad: A Theoretical Approach. Economic Record 27, 13-15.

Manasse, P. and Turrini, A. (2001) Trade, Wages, and 'Superstars'. Journal of International Economics 54, 97-117.

Martin, P. and Ottaviano, G. (2001) Growth and Agglomeration. International Economic Review 42, 947-68.

Miles, D. and Scott, A. (2005) Macroeconomics - Understanding the Wealth o Nations. Chichester: John Wiley Sons, Ltd.

Mills, E.S. (1967) An Aggregative Model of Resource Allocation in Metropolitan Areas. American Economic Review 57, 197-210.

Muth, R.F. (1969) Cities and Housing. Chicago: University of Chicago Press.

Muth, R.F. (1973) A Vintage Model of the Housing Stock. Papers of the Regional Science Association 30, 141-156.

Naito, T. and Ohdoi, R. (2011) A Two-Country Model of Trade and Growth with Intersectoral Knowledge Spillovers. Journal of Economics 103, 39-59.

Nakajima, T. (2003) Catch-up in Turn in a Multi-Country International Trade Model with Learning-by-Doing and Intervention, Journal of Development Economics 72, 117-38.

Nishimura, K. and Shimomura, K. (2002) Trade and Indeterminacy in a Dynamic General Equilibrium Model. Journal of Economic Theory 105, 244-60.

Nocco, A. (2005) The Rise and Fall of Regional Inequalities with Technological Differences and Knowledge Spillovers. Regional Science and Urban Economics 35, 542-69. 
Obstfeld, M. and K. Rogoff (1998) Foundations of International Macroeconomics. Mass., Cambridge: MIT Press.

O’Hara, D.J. (1977) Location of Firms Within a Square Central Business District. Journal of Political Economy 85, 1189-207.

Oniki, H. and Uzawa, H. (1965) Patterns of Trade and Investment in a Dynamic Model of International Trade. Review of Economic Studies 32, 15-38.

Papageorgiou, Y.Y. and Smith, R.R. (1983) Agglomeration as Local Instability of Spatially Uniform Steadt-States. Econometrica 51, 1109-19.

Rabenau, B.V. (1979) Urban Growth with Agglomeration Economics and Diseconomics. Geographia Polonica 42, 77-90.

Richardson, B.V. (1973) Regional Growth Theory. New York: John Wiley.

Robert-Nicound, F. (2004) The Structure of Simple 'New Economic Geography’ Models (or, On Identical Twins). Journal of Economic Geography 5, 201-34.

Solow, R. (1956) A Contribution to the Theory of Growth. Quarterly Journal of Economics 70, 65-94.

Solow, R.M. (1973) On Equilibrium Models of Urban Location, in Essays in Modern Economics, edited by Parkin, M. London: Longman.

Sorger, G. (2002) On the Multi-Country Version of the Solow-Swan Model. The Japanese Economic Review 54, 146-64.

Tabuchi, T. and Thisse, J.F. (2002) Taste Heterogeneity, Labor Mobility and Economic Geography. Journal of Development Economics 69, 155-77.

Upton, C. (1981) An Equilibrium Model of City Size. Journal of Urban Economics 10, 15-36.

Valdés, B. (1999) Economic Growth - Theory, Empirics and Policy. Cheltenham: Edward Elgar.

Vellutini, C. (2003) Capital Mobility and Underdevelopment Traps. Journal of Development Economics 71, 435-62.

Wheaton, W.C. (2004) Commuting, Congestion, and Employment Dispersal in Cities with Mixed Land Use. Journal of Urban Economics 55, 417-38.

Wong, K.Y., 1995. International Trade in Goods and Factor Mobility, Mass., Cambridge: MIT Press.

Zhang, W.B. (1993) A Woman's Labor Participation and Economic Growth: Creativity, Knowledge Utilization and Family Preference. Economics Letters 42, 105-110. 
Zhang, W.B. (1995) Leisure Time, Savings and Trade Patterns - A Two-Country Growth Model. Economic Modelling 12, 425-434.

Zhang, W.B. (2008a) International Trade Theory: Capital, Knowledge, Economic Structure, Money and Prices over Time and Space. Berlin: Springer.

Zhang, W.B. (2008b) Growth and Residential Distribution with Economic Structure and Amenity: A Synthesis of Solow-Uzawa's Growth, Alonso’s Urban, and Muth's Housing Models. Papers in Regional Science 87, 277-303. 